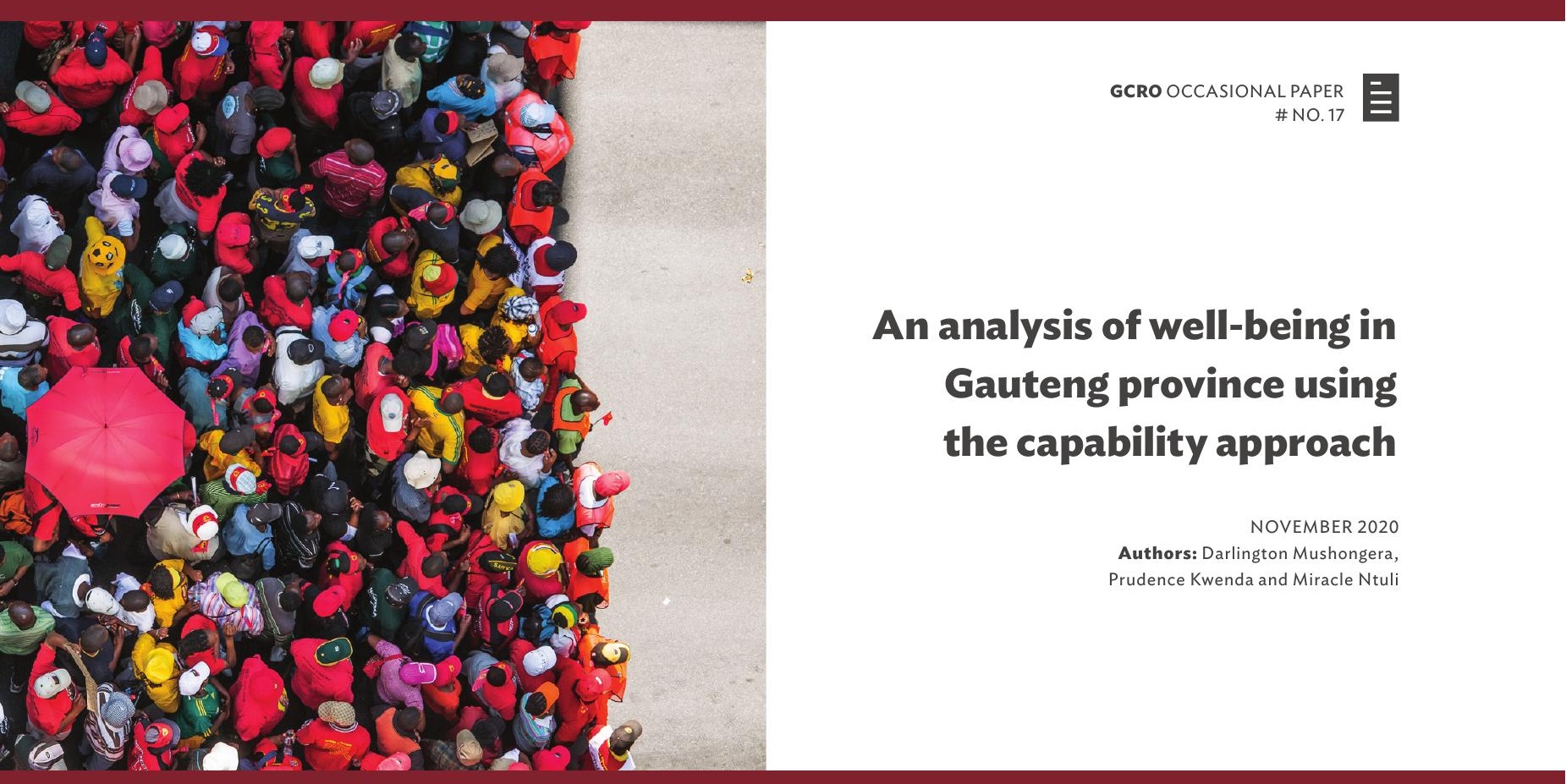


The GCRO comprises a partnership of:

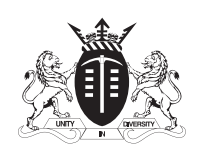

GAUTENG PROVINCIAL GOVERNMENT
REPUBLIC OF SOUTH AFRICA

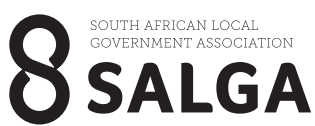

Inspiring service delivery

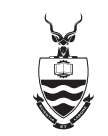

WITS

UNIVERSITY

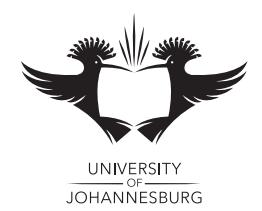

AN ANALYSIS OF WELL-BEING

IN GAUTENG PROVINCE USING

THE CAPABILITY APPROACH

Publishers: Gauteng City-Region Observatory

(GCRO), a partnership of the University of

Johannesburg, the University of the Witwatersrand,

Johannesburg, the Gauteng Provincial Government

and organised local government in Gauteng (SALGA).

(C) GCRO, November 2020
Authors: Darlington Mushongera,

Prudence Kwenda and Miracle Ntuli

Editor: Julia de Kadt

Maps: Samkelisiwe Khanyile

Design: Breinstorm Brand Architects

Production manager: Simon Chislett

Cover image: Alastair Mclachlan

DOI: $10.36634 / 2020.0 p .1$

ISBN: 978-1-990972-09-6 (XML)

ISBN: 978-1-990972-10-2 (Web pdf) 


\section{An analysis of well-being in Gauteng province using the capability approach}

NOVEMBER 2020

Authors: Darlington Mushongera, Prudence Kwenda and Miracle Ntuli 


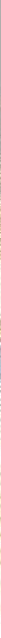

\section{Contents}

Figures and tables.

Acronyms and abbreviations...

EXECUTIVE SUMMARY

2

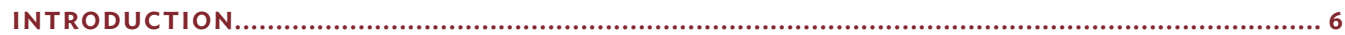

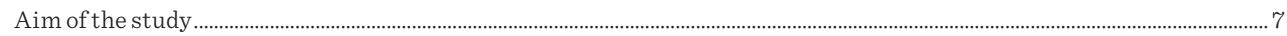

Gauteng province

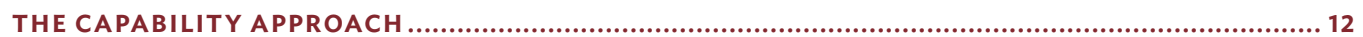

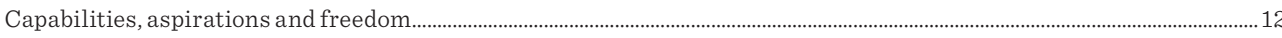

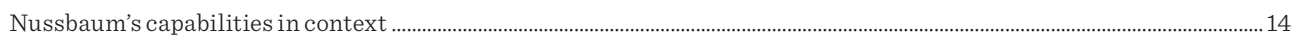

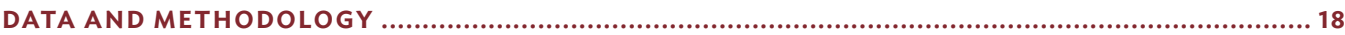

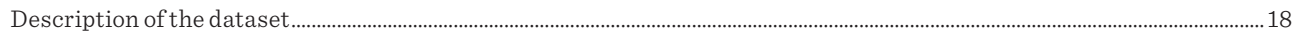

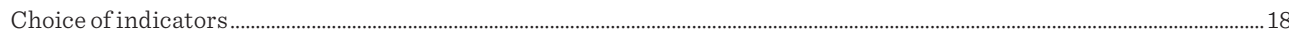

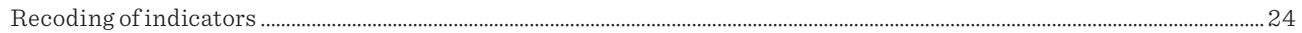

Methodology

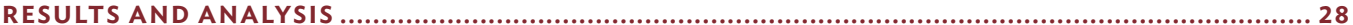

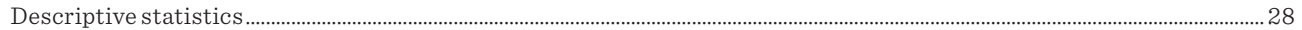

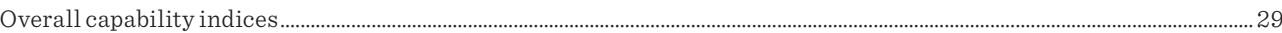

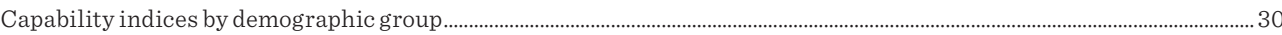

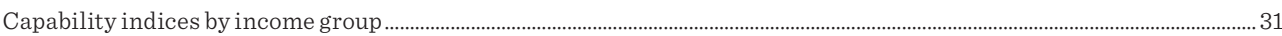

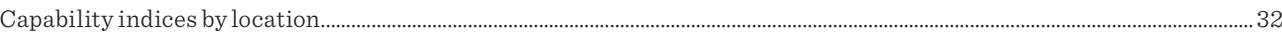

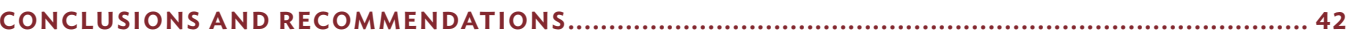

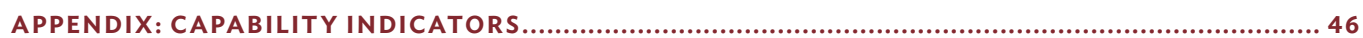

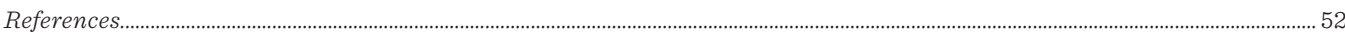

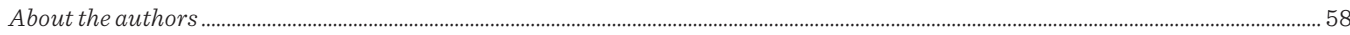




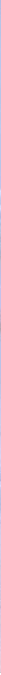

\section{Figures and tables}

\section{FIGURES}

Figure 1: Map of Gauteng province (pre-2016 municipal boundaries) 9

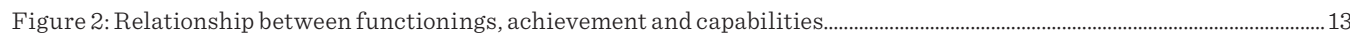

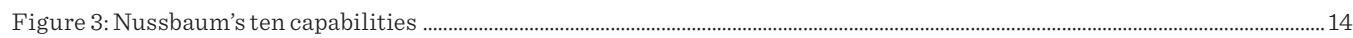

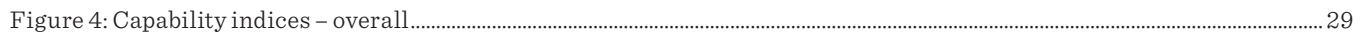

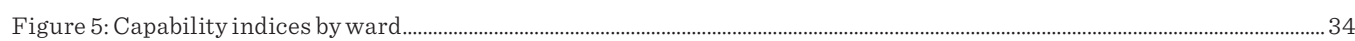

\section{TABLES}

Table 1: The eight capabilities and their corresponding indicators .................................................................................................................... 19

Table 2: Capability indices by demographic group ........................................................................................................................................... 30

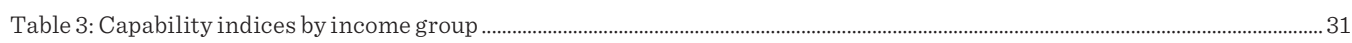

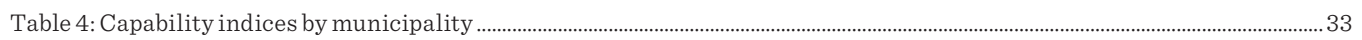

Table A: Capability indicators - descriptive statistics and weights.......................................................................................................... 46

\section{Acronyms and abbreviations}

$\begin{array}{ll}\text { CI } & \text { capability index } \\ \text { GCR } & \text { Gauteng City-Region } \\ \text { GCRO } & \text { Gauteng City-Region Observatory } \\ \text { GDP } & \text { gross domestic product } \\ \text { HDCA } & \text { Human Development Capability Association } \\ \text { MCA } & \text { multiple correspondence analysis } \\ \text { QoL } & \text { Quality of Life }\end{array}$



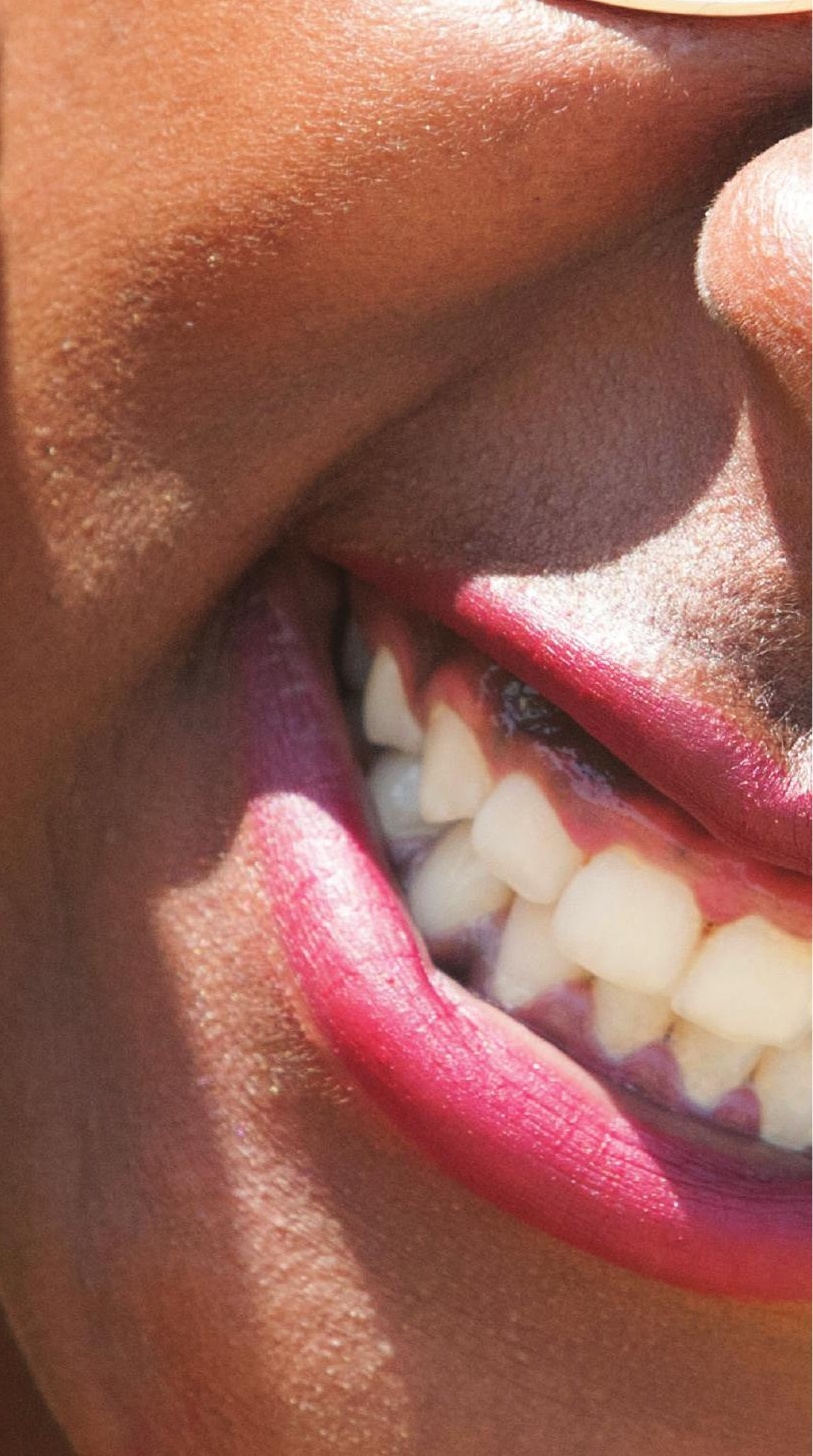



\section{Executive summary}

The purpose of this occasional paper is to analyse well-being in Gauteng province from a capability perspective. We adopt a standard 'capability approach' consistent with Amartya Sen's concept of capabilities $(1985 ; 1993 ; 1999)$. This study builds on earlier research on poverty and inequality in the Gauteng City-Region (GCR) focusing on income inequality (Tseng, 2018), labour market inequalities (Kwenda \& Benhura, 2018) and multidimensional poverty (Mushongera et al., 2017; Mushongera et al., 2018). These analyses were based mainly on objective characteristics of well-being, such as income, employment, housing and schooling. However, adopting a capability approach provides us with a more holistic view of well-being in Gauteng by focusing simultaneously on both objective and subjective aspects.

According to Robeyns (2016, p. 1), the capability approach is

\begin{abstract}
a theoretical framework that entails two core normative claims: first, the claim that the freedom to achieve well-being is of primary moral importance, and second, that freedom to achieve well-being is to be understood in terms of people's capabilities, that is, their real opportunities to do and be what they have reason to value.
\end{abstract}

Writing from a feminist and social justice perspective, Nussbaum (2003) generated a list of what she considered the most central capabilities. These capabilities are relevant to the analysis of well-being in general, and generate useful insights that can potentially provide an additional lens within the policy realm. They can be combined into indices that capture 'functionings', or the 'hard' and 'soft' indicators of well-being.

Out of the ten capabilities suggested by Nussbaum (2003), our analysis is based on eight, namely 'play', 'emotions', 'other species', 'affiliation', 'bodily health', 'bodily integrity', 'senses, imagination and thought' and 'control over one's environment'.
The analysis uses data from the Gauteng City-Region Observatory Quality of Life (GCRO QoL) Survey IV-2015/16 (GCRO, 2016), which asks a wide range of questions, and the response options vary significantly. For instance, some questions have binary responses while others have multiple possible responses, such as those captured by a Likert scale. To generate similar units of measurement, all indicators were normalised using a standard ordinal ranking procedure. Normalisation is a simple technique whereby all variables are scored consistently so that the lowest rank always indicates the worst outcomes and the highest means the best in relative terms; for example, for the Health Status Indicator, a rank of 1 is assigned to individuals with very poor health; 2 for poor health; 3 for good health; and 4 for excellent health (OECD, 2008). Each capability index in our analysis was computed as a weighted average of its related normalised indicator variables. The weights were generated using multiple correspondence analysis (MCA), which is an objective statistical approach.

The results of our analysis indicate that the capabilities with high scoring indices are 'play' and 'senses, imagination and thought', while 'bodily integrity' and 'affiliation' scored very low.

Capability achievements vary across race, age, gender, income level and location. The results confirm the well-known heterogeneity in human conditions among South African demographic groups. However, we observe broader (in both subjective and objective dimensions) levels of deprivation that are otherwise masked in earlier studies.

Policies that directly target indicators for capabilities where historically disadvantaged and vulnerable groups (such as youth, elderly and the physically challenged) are deprived are highly recommended. Given the spatial heterogeneities in capability achievements, we recommend localised interventions in capabilities that are lagging in certain areas of the province. 


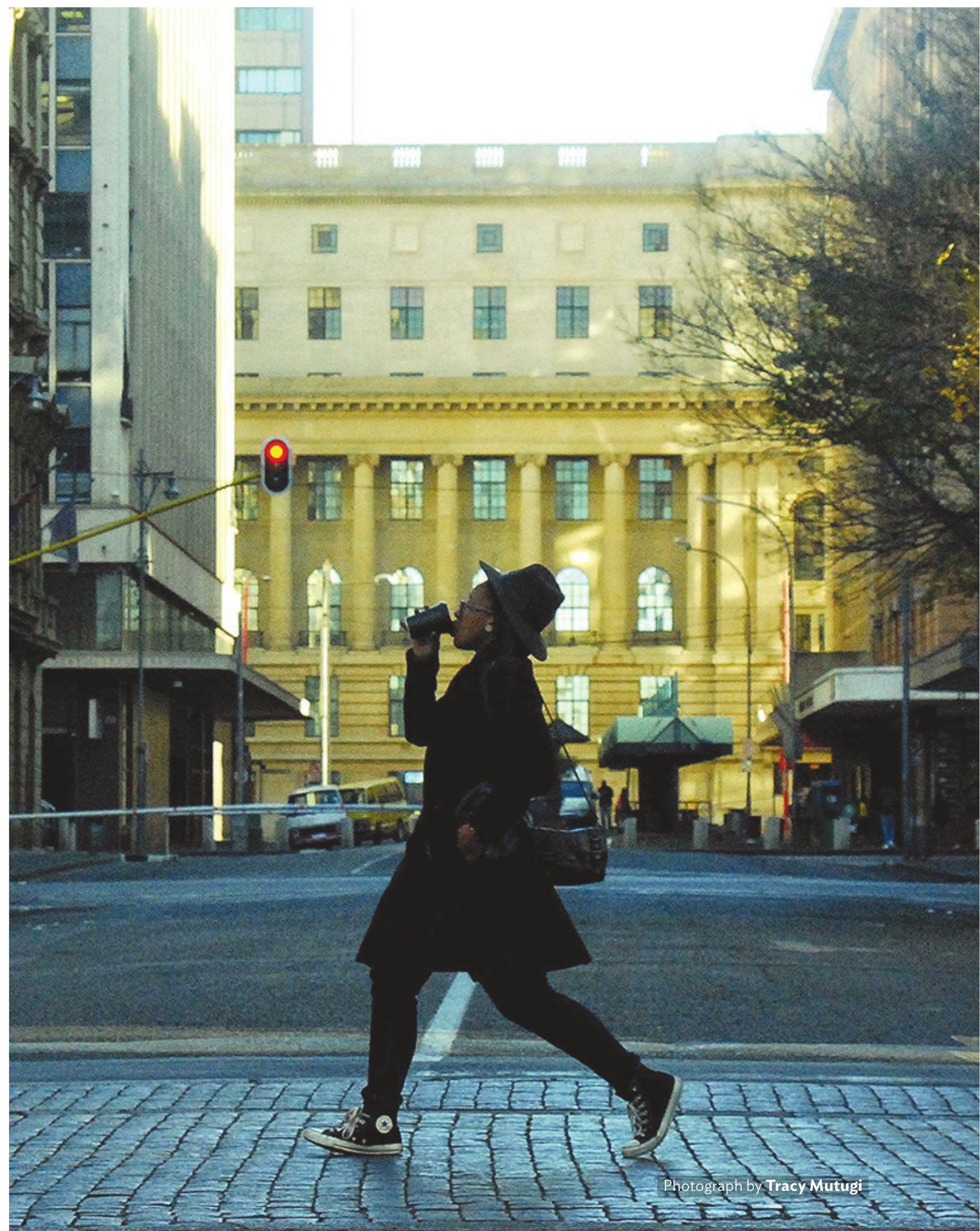




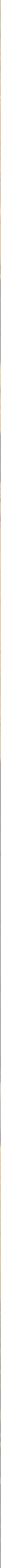




\section{Introduction}

As countries across the globe pursue economic development, the improvement of individual and societal well-being has increasingly become an overarching goal. In the global South, in particular, high levels of poverty, inequality and deteriorating social fabrics remain significant challenges (ILO, 2013; UN, 2020; WEF, 2020). Programmes and projects for addressing these challenges have had some, but limited, impact (Francis \& Webster, 2019; Friedman \& Bhengu, 2008; World Bank, 2018; Zizzamia et al., 2019).

Understanding poverty and well-being has been an area of active research at the Gauteng City-Region Observatory (GCRO). To date, several research outputs based on conventional methods of analysis have been published, and these show both the levels and the spatial distribution of poverty in Gauteng province (e.g. Katumba et al., 2019; Mushongera et al., 2018; Tseng, 2018). The traditional objective approaches of analysing poverty and well-being (e.g. unidimensional money-metric and multidimensional measures) have no doubt yielded policy prescriptions (such as social support and basic service delivery) that have influenced people's lives in positive ways. However, there have been some shortcomings which are accounted for by the 'capability approach' postulated by Sen $(1985 ; 1993 ; 1999)$. First, development in countries across the world has traditionally been evaluated using the economic measure of gross domestic product (GDP), which allows for comparison across nations. However, the GDP measure has limitations when it comes to assessing the impact of development on individual and societal wellbeing because of the fallacy that more money means higher well-being (Costanza et al., 2007). Although essential, income and economic growth are not ends in themselves (Daly \& Posner, 2011; Fioramonti, 2014;
Stiglitz et al., 2009). The capability approach, on the other hand, offers an opportunity to focus on what constitutes well-being, thereby allowing more precise evaluation of whether developmental inputs are translating into outputs that are subjectively experienced as better welfare (Kimhur, 2020). In addition, the capability approach also draws our attention to the process through which people achieve various aspects of well-being in their lives by emphasising people's values and the freedom they have to pursue those values (Alkire, 2011).

Other approaches of measuring well-being (discussed below) have also emerged in recent years, and these attempt to capture essential aspects of well-being (such as life expectancy, life satisfaction, feelings of security, etc.) that cannot be inferred from the GDP measure. However, these approaches consider the objective and subjective aspects of well-being in isolation. In reality, well-being is more complex than suggested by these two dichotomies, and hence they limit the possibility of obtaining a holistic view of well-being (Veenhoven, 2007). An overarching framework that combines both approaches, as well as incorporating people's aspirations and freedom, offers this holistic view and is therefore warranted. One such attempt is the 'capability approach', first conceptualised by $\operatorname{Sen}(1985 ; 1993 ; 1999)$ and then operationalised by Nussbaum (2000a; 2000b; 2003). According to Robeyns (2016, p. 1), the capability approach is

\footnotetext{
a theoretical framework that entails two core normative claims: first, the claim that the freedom to achieve well-being is of primary moral importance, and second, that freedom to achieve well-being is to be understood in terms of people's capabilities, that is, their real opportunities to do and be what they have reason to value.
} 
Today, numerous studies of individual well-being inspired by the capability approach have been published. However, many of these studies capture aspects of the capability approach in a piecemeal way due to the nature of the available data. For instance, motivated by the capability approach, researchers often compute composite social exclusion indices to evaluate well-being (e.g. Koo \& Lee, 2015; Rippin, 2016). Unfortunately, the computation of a composite index causes the resulting analyses to lose the essence of what Sen envisaged and what ten core capabilities suggested by Nussbaum (2003) attempt to capture, that is, a range of personal aspirations and the freedom to achieve them. Similar studies on the South African case also follow this trend, for example Klasen (1997; 2000), Higgs (2007), and Greyling and Tregenna (2017). These studies generally compute aggregated indices of well-being and then assess patterns across demographic groups and locations.

Valuable policy insights have emerged from these studies concerning the quality of life and the heterogeneity of well-being at national and subnational levels. However, they fall short in providing a holistic view of well-being compared to what is possible to derive from a standard capability approach framework that emphasises aspirations and freedoms.

The GCRO Quality of Life (QoL) Survey IV-2015/16 (GCRO, 2016), to a larger extent, provides a rich dataset for undertaking an analysis of well-being using the capability approach framework.

\section{Aim of the study}

In this occasional paper, we analyse well-being in Gauteng using a capability approach. We implement a standard capability approach consistent with
Sen's view, namely that evaluation of well-being should be based primarily on the extent of the freedom that people have to promote or achieve the 'functionings' they value (Alkire, 2011; Sen 1985; 1993; 1999). The study builds on earlier research on poverty and inequality by the GCRO that focused on income inequality (Tseng, 2018), labour market inequalities (Kwenda \& Benhura, 2018) and multidimensional poverty (Mushongera et al., 2017; Mushongera et al., 2018). These analyses were based largely on objective characteristics of well-being such as income, employment, housing and schooling. By adopting a capability approach, we hope to capture other important dimensions of well-being not fully accounted for in earlier studies. The biennial GCRO QoL surveys have come closest to collecting data suitable for analysing several indicators from the Nussbaum (2003) list of capabilities.

Based on the GCRO QoL Survey IV-2015/16 dataset (GCRO, 2016), we computed eight capability indices from the list of ten suggested by Nussbaum. Each index is based on individual 'functionings' that deliberately cover both 'hard' and 'soft' indicators of well-being undergirded by the assumption of aspirations and freedom. Unlike previous studies which simply aggregate functionings into a composite index, we place particular attention on the connections between functionings to generate an index for each capability. From these computations, we assess capability achievements across gender, race, age, income level and geographic location, and suggest policy interventions where achievement levels indicate deprivation.

In the remainder of this section, we provide a brief background to Gauteng province.

\section{The capability approach offers an opportunity to focus on what constitutes well-being}




\section{Gauteng province}

Gauteng is one of the nine provinces of South Africa. Although it is the smallest province in terms of size, it has the largest share of the national population - 25.8 percent in 2019 - and accounts for 35 percent of the national economy (StatsSA, 2019a).

The province is mainly urban and comprises three of the country's largest metropolitan municipalities, namely the financial hub, the City of Johannesburg; the national administrative capital, the City of Tshwane; and Ekurhuleni, a major industrial hub. In 2015, there were seven other municipalities located in the province's southern and western areas, namely Lesedi, Midvaal, Emfuleni, Mogale City, Merafong City, Westonaria and Randfontein (Mushongera et al., 2017; StatsSA, 2018). Westonaria and Randfontein have since been merged into a single municipality called Rand West. Our analysis treats them separately, based on data collected before the merger.

The province attracts a large number of migrants, causing a relatively rapid increase in population compared to other provinces. Migration has shaped the size and socio-economic structure of the province. Despite the notable increase in population of 7.8 million in 1996 to an estimated 15.4 million in 2020, Gauteng has managed to maintain service delivery at reasonable levels over the years (StatsSA, 2020). For example, over 90 percent of the population had adequate sanitation and access to piped water in 2017/18 (GCRO, 2018). However, the rising population in the province is likely to compromise service delivery into the future as municipalities struggle to keep up with the demand.

Unemployment, poverty and inequality are also defining features of Gauteng. For example, in 2019, the unemployment rate stood at 31 percent while the Gini coefficient was over 0.70 (own calculations on GCRO, 2018; StatsSA, 2019b).

The racial policy pursued under apartheid has left South Africa with a racially fragmented socioeconomic fabric. Consequently, income differences and poverty patterns are closely linked to race. Black Africans, in particular, were highly disadvantaged by apartheid, lacking freedom of access to those fundamental rights (e.g. education, housing, sanitation) necessary for attaining a decent standard of living. In 1996, South Africa adopted a non-racial Constitution that affirms the democratic values of human dignity, equality and freedom (RSA, 1996). A legal framework was established in which individuals were accorded freedom as a matter of law.

Much of the responsibility to deliver basic services to the public, reverse the apartheid legacy and ensure equitable access to basic services is the mandate of local government. However, municipalities often complain that some of the mandates they are expected to carry out are either underfunded or completely unfunded, especially in the housing and health sectors (FFC, 2014; Ntenga, 2011). As a result of this funding crisis, service delivery is compromised and the capabilities of many previously disadvantaged communities are diminished. The GCRO QoL Survey IV-2015/16 (GCRO, 2016) showed that rates of satisfaction with local government at the time were in decline because some municipalities were failing to resolve service delivery deficits. ${ }^{1}$ Nationally, yearly protests over service delivery escalated from 34 to 247 between 2005 and 2018, with the majority of the protests occurring in Gauteng, signalling the challenges in service delivery that municipalities face (Municipal IQ, 2019). ${ }^{2}$ Apart from basic service delivery problems, Gauteng, in general, is also known for high rates of crime as well as high perceptions of crime, which both compromise safety and security. Gated communities have been on the rise and are an expression of a lack of faith in government to provide secure neighbourhoods (Harrison \& Mabin, 2006; Landman \& Badenhorst, 2015). There are also concerns over the lack of social cohesion, which results in racially charged and xenophobic tendencies (Abrahams, 2016; Ballard et al., 2019).

1 However, the GCRO QoL V-2017/18 survey registered some improvement in satisfaction (GCRO, 2018).

2 Municipal IQ is a web-based data and intelligence service specialising in the monitoring and assessment of South Africa's 283 municipalities. 
INTRODUCTION

Figure 1: Map of Gauteng province (pre-2016 municipal boundaries)

DATA SOURCES: Municipal Demarcation Board (2011) Local municipalities; Municipal Demarcation Board (2011) Gauteng boundary; Municipal Demarcation Board (2011) Provincial boundaries.
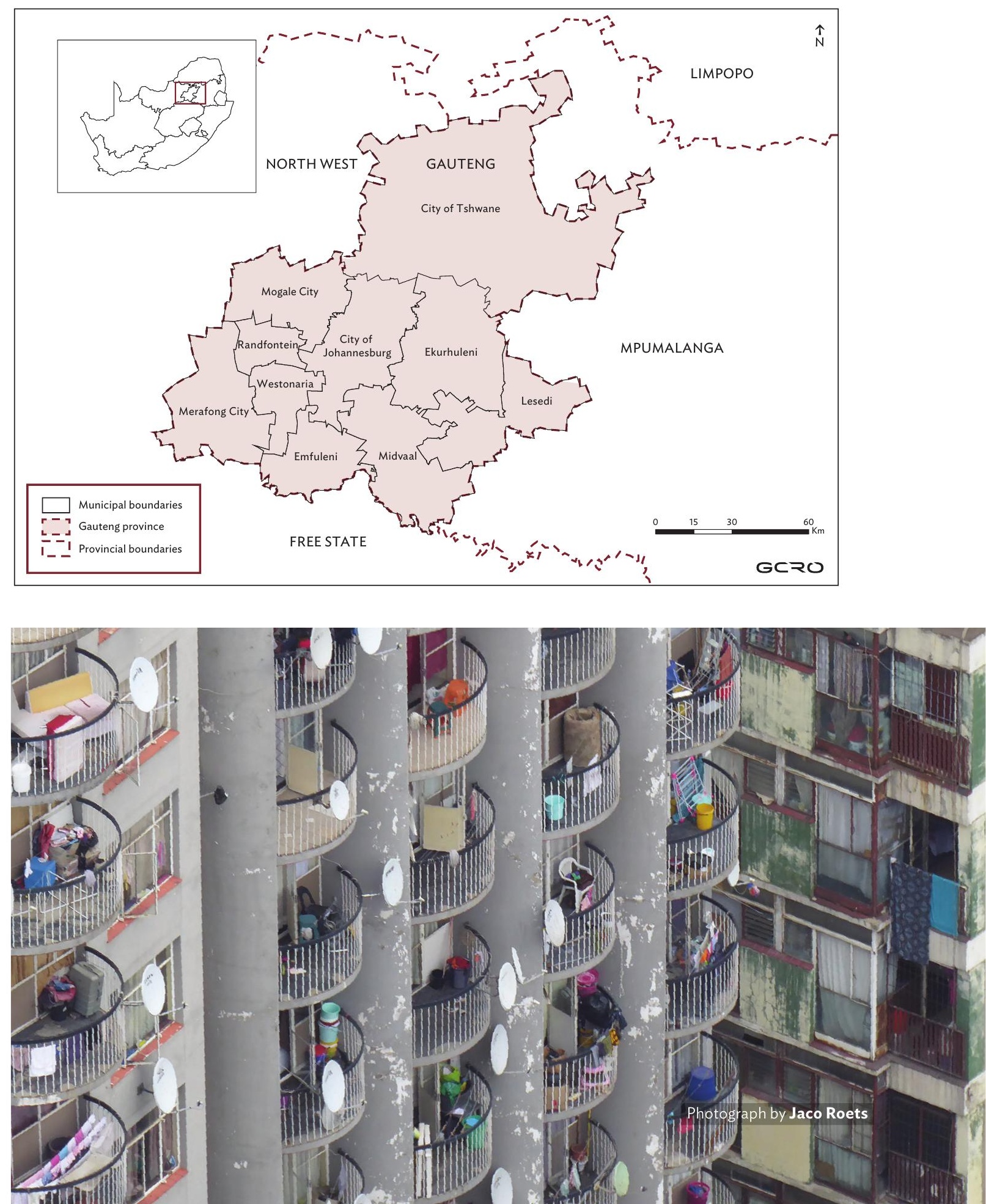

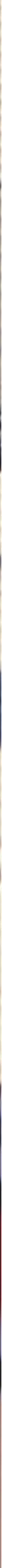


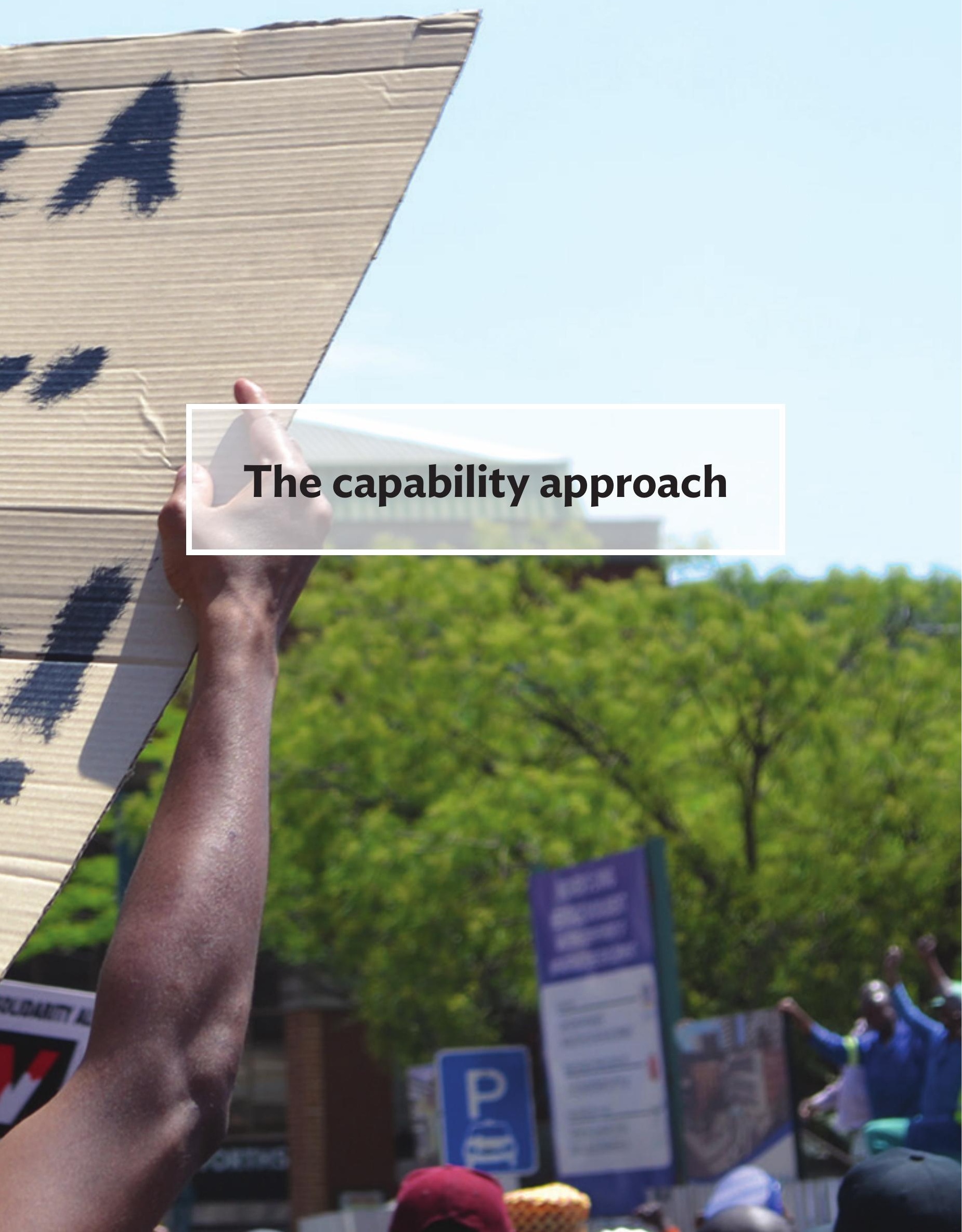




\section{The capability approach}

\section{Capabilities, aspirations and freedom}

The ‘capability approach' is a normative framework for conceptualising and appraising welfare issues such as poverty and inequality (Kimhur, 2020; Robeyns, 2005). Developed by Amartya Sen (1985; 1993; 1999), the approach was an attempt to address the shortcomings of traditional methods of analysing poverty which overlooked the diverse, plural and multidimensional nature of human conditions and experiences. According to Sen (2000, p. 18):

\footnotetext{
Human lives are battered and diminished in all kinds of different ways, and the first task, seen in this perspective, is to acknowledge that deprivations of very different kinds have to be accommodated within a general overarching framework. The general framework must be compelling and coherent but must not try to overlook the pluralities that are crucially involved (in the diverse nature of deprivations) in a misguided search for some one measure of success or failure, some single clue to all the other disparity concerns.
}

While multidimensional poverty studies take cognisance of the plurality of poverty by examining a diverse set of conditions (e.g. access to housing, water, level of education), they fall short of fully capturing the intrinsic dimensions of human well-being due to the lack of appropriate datasets that capture the 'softer' aspects of well-being. In recent times, there has been an increase in measures that capture these intrinsic values, including indices such as the Social Progress Index ${ }^{3}$ (Porter et al., 2015), the Happiness Index ${ }^{4}$ and the Quality of Life Index (Mushongera,
2017). While composite indices are informative, disaggregated indices for specific dimensions of wellbeing provide a higher level of detail. The capability approach goes a step further by emphasising a detailed analysis of each capability.

From a capability perspective, individual wellbeing is considered to be dependent on 'functionings'. Functionings capture what individuals effectively want to do and to be (i.e. their aspirations) - for example to work, to learn, to be educated and to enjoy life. A set of functionings coupled with the freedom to attain them constitutes a capability, for example capabilities of bodily health, bodily integrity and control over one's environment (Bookwalter \& Dalenberg, 2004; Koo \& Lee, 2015; Robeyns, 2005; Sen, 1985). Figure 2 shows this relationship between functionings, achievement and capabilities.

Capabilities vary across individuals due to differences in their freedoms and preferences. For Kimhur (2020), the capability approach proposes capabilities as a space for evaluating or comparing individuals' advantages and deprivations. This can be rationalised by the concept of conversion factors, which suggests that individuals possess different abilities to convert resources (means) into capabilities or functionings (ends). For instance, when presented with the same amount of food, different individuals can convert it into different outcomes (e.g. being able to be nourished) depending on personal factors such as metabolic rate or disability, or the power to take the provided food without the influence of social factors (e.g. gender inequality within a household).

By acknowledging human diversity, the capability approach serves as an essential basis for comparing welfare across demographic groups. In so doing, it distinguishes groups that are able to more efficiently

3 The Social Progress Index is registered as a non-profit organisation in the United States.

4 The World Happiness Report is a landmark survey of the state of global happiness that ranks 156 countries by how happy their citizens perceive themselves to be. The first report was published in 2013. 
Figure 2: Relationship between functionings, achievement and capabilities SOURCE: Adapted from Robeyns (2017)

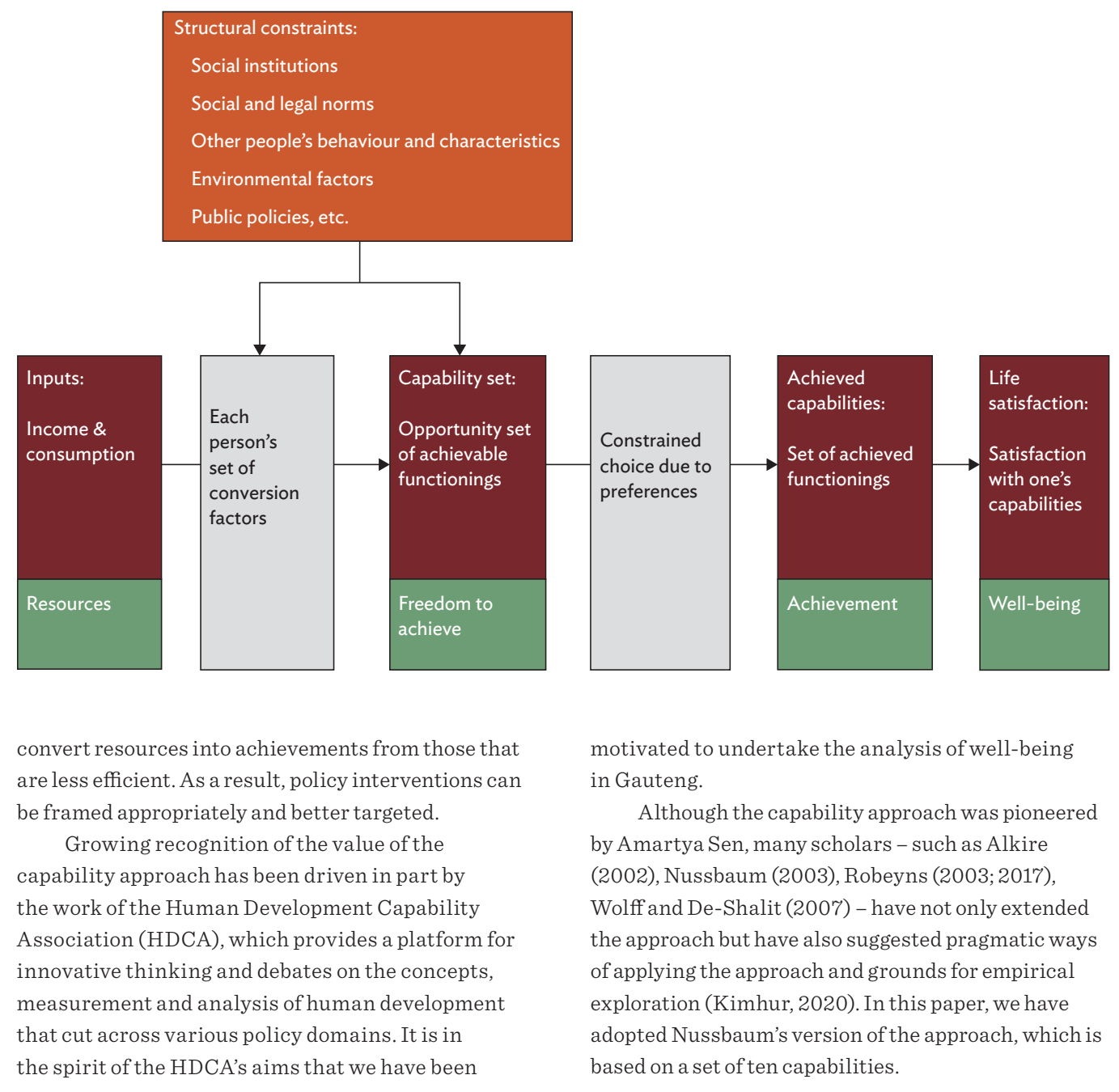

\section{By acknowledging human diversity, the capability approach serves as an essential basis for comparing welfare across demographic groups}




\section{Nussbaum's capabilities in context}

Nussbaum (2003), writing from a feminist and a social justice perspective, generated a list of ten capabilities that are also relevant to an analysis of well-being. These capabilities give useful insights that can potentially cause a paradigm shift within the policy realm. The ten central human capabilities which Nussbaum (2003, pp. 41-42) identified are listed in the box on the next page.

In the absence of readily available datasets that speak directly to most of the capabilities that Nussbaum identified, we decided to use proxy variables that reasonably capture the essence of the capabilities she envisaged. In any case, Nussbaum's list of ten capabilities was not designed to be definitive, but rather tentative and revisable (Nussbaum, 2003). However, because we could not find suitable proxies from our data for 'life' and 'practical reason', we omitted them and analysed only eight of Nussbaum's capabilities.

For each of the eight capabilities, we identified a set of measurable indicators that we found to be the closest proxies, based on variables in the QoL IV-2015/16 dataset (GCRO, 2016). The number of indicator variables (proxies) for each capability varied depending on the available data. To ensure that the imbalance in the number of proxies per capability did not accord more weight to those capabilities with more proxies, a standardised single index was generated for each capability.

Figure 3 presents the full set of Nussbaum's ten capabilities, with the eight we selected for our analysis of well-being in Gauteng. The set of indicators corresponding to each capability's related functionings is outlined in Table 1 in the next section.

Figure 3: Nussbaum's ten capabilities

SOURCE: Adapted from Nussbaum (2003)

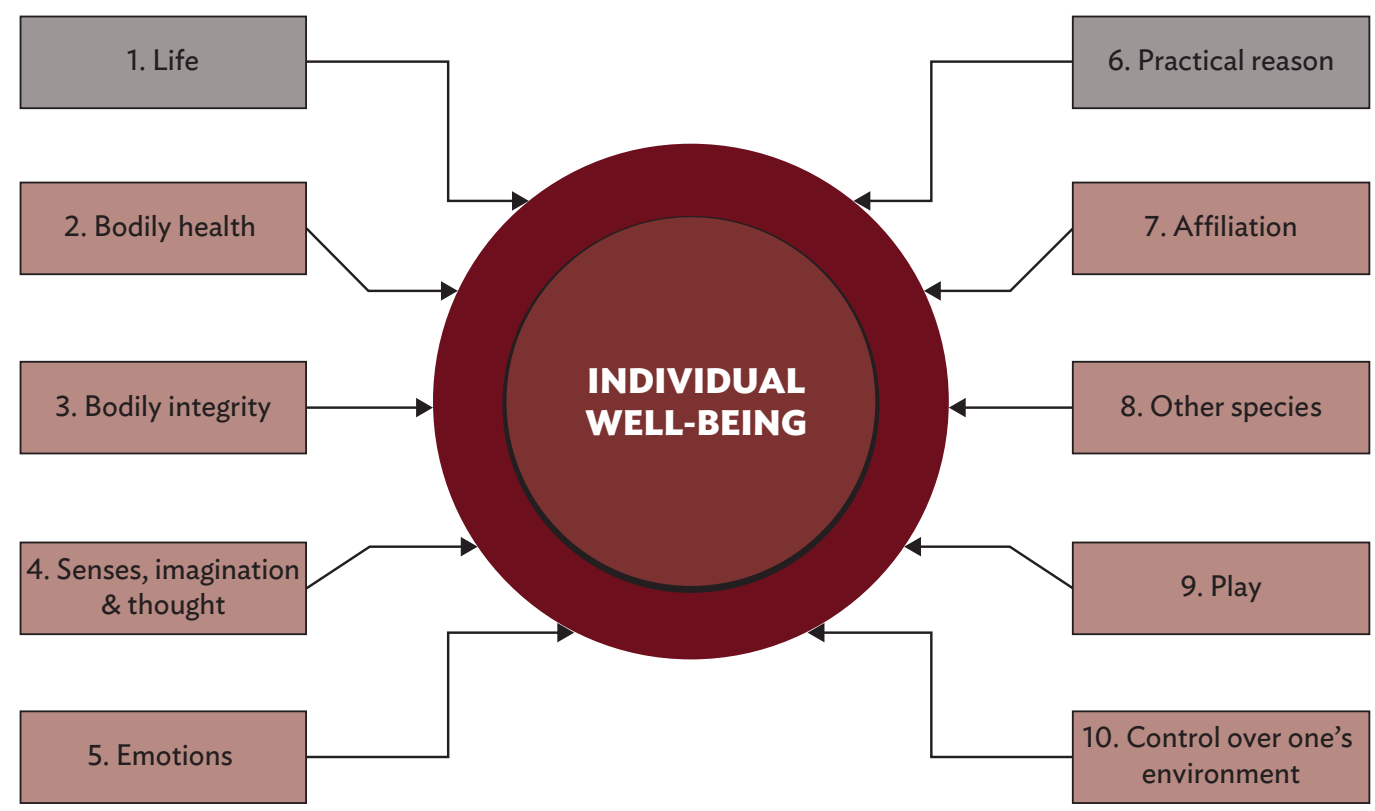

Excluded in this paper for lack of suitable proxies 


\section{Central human capabilities (adapted from Nussbaum, 2003)}

\section{Life}

Being able to live to the end of a human life of normal length, not dying prematurely, or before one's life is so reduced as to be not worth living.

\section{Bodily health}

Being able to have good health, including reproductive health; to be adequately nourished; to have adequate shelter.

\section{Bodily integrity}

Being able to move freely from place to place; to be secure against violent assault, including sexual assault and domestic violence; having opportunities for sexual satisfaction and choice in matters of reproduction.

\section{Senses, imagination and thought}

Being able to use the senses, to imagine, think and reason - and to do these things in a 'truly human' way, a way informed and cultivated by an adequate education, including, but by no means limited to, literacy and basic mathematical and scientific training. Being able to use imagination and thought in connection with experiencing and producing works and events of one's own choice, religious, literary, musical, and so forth. Being able to use one's mind in ways protected by guarantees of freedom of expression concerning both political and artistic speech, and freedom of religious exercise. Being able to have pleasurable experiences and to avoid non-beneficial pain.

\section{Emotions}

Being able to have attachments to things and people outside ourselves; to love those who love and care for us, to grieve at their absence; in general, to love, to grieve, to experience longing, gratitude and justified anger. Not having one's emotional development blighted by fear and anxiety. (Supporting this capability means supporting forms of human association that can be shown to be crucial in their development.)

\section{Practical reason}

Being able to form a conception of the good, and to engage in critical reflection about the planning of one's life. (This entails protection for the liberty of conscience and religious observance.)

\section{\%. Affiliation}

Being able to live with and toward others, to recognise and show concern for other human beings, to engage in various forms of social interaction; to be able to imagine the situation of another. (Protecting this capability means protecting institutions that constitute and nourish such forms of affiliation, and protecting the freedom of assembly and political speech.); Having the social bases of self-respect and nonhumiliation; being able to be treated as a dignified being whose worth is equal to that of others. This entails provisions of non-discrimination based on race, gender, sexual orientation, ethnicity, caste, religion, national origin.

\section{Other species}

Being able to live with concern for and in relation to animals, plants and the world of nature.

\section{Play}

Being able to laugh, to play, to enjoy recreational activities.

\section{Control over one's environment}

Political: Being able to participate effectively in political choices that govern one's life; having the right of political participation, protections of free speech and association; Material: Being able to hold property (both land and movable goods), and having property rights on an equal basis with others; having the right to seek employment on an equal basis with others; having the freedom from unwarranted search and seizure. In work, being able to work as a human being, exercising practical reason, and entering into meaningful relationships of mutual recognition with other workers. 


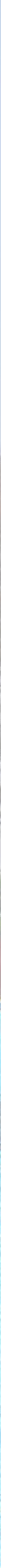




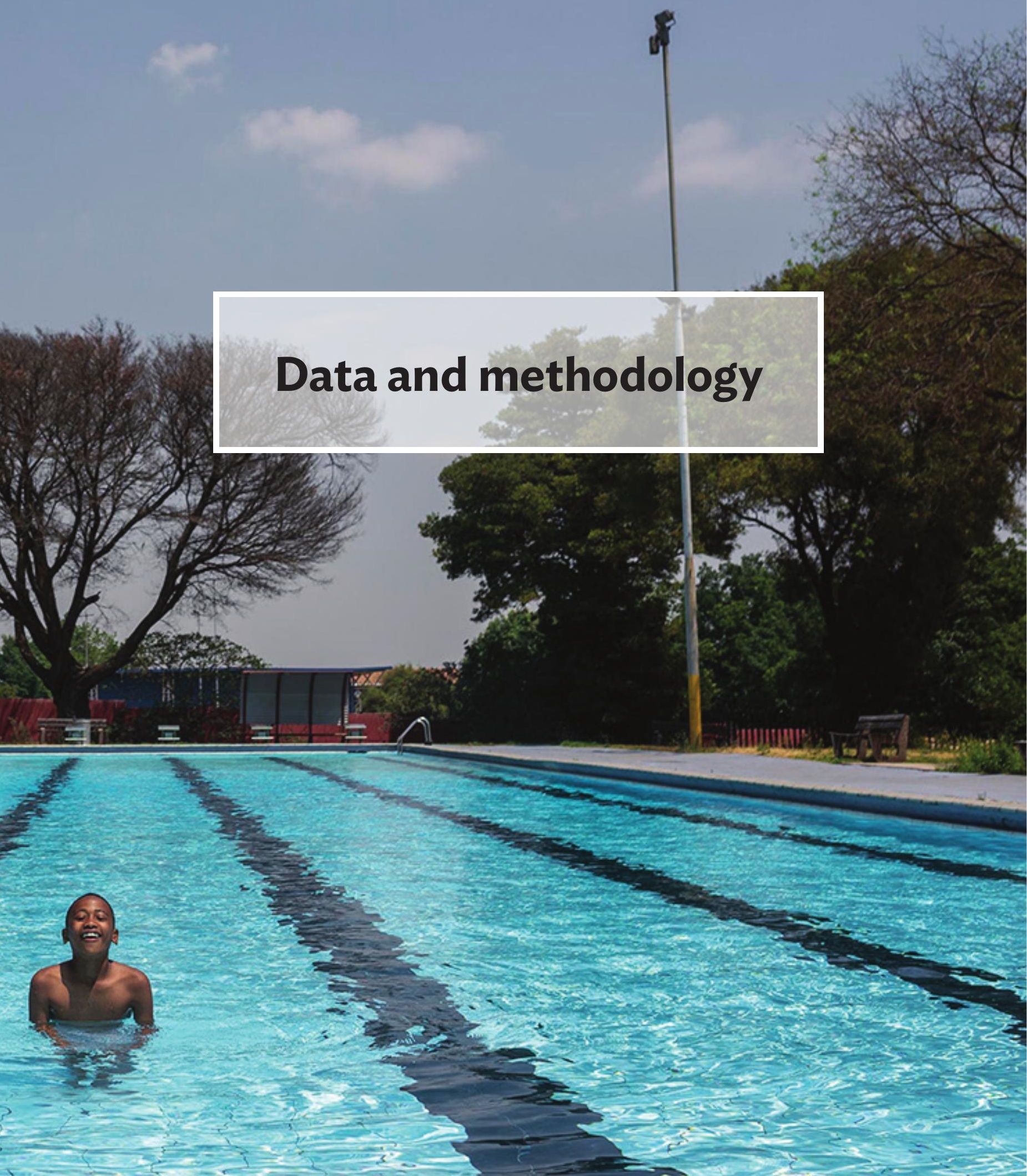




\section{Data and methodology}

\section{Description of the dataset}

Our study uses data from the QoL Survey IV-2015/16 (GCRO, 2016) conducted by the GCRO. The survey measures the quality of life of residents in Gauteng through the lenses of health and well-being, economic circumstances, housing and perceptions of service delivery, crime and safety, community and public participation, psychosocial attitudes, satisfaction with government, transport and mobility, local community and neighbourhood dynamics, and political and social values and attitudes. Data were collected from a random sample of 30002 respondents across all 529 wards in Gauteng, which makes QoL IV-2015/16 (GCRO, 2016) one of the largest living-conditions surveys in South Africa (Mushongera et al., 2017).

The data collection process utilised geo-located face-to-face interviews based on questionnaires programmed in computer-assisted personal interviewing software. Incoming data were subjected to rigorous quality control measures, such that some recoding and corrections were made during the data validation process (AskAfrica, 2016; AskAfrika \& GCRO,2016). The data were then weighted to adjust for the sample design and for population distribution (ward, race and gender) based on the 2011 South African Census. The dataset captures both objective and subjective elements best suited for analysing wellbeing as per Nussbaum's (2003) ten core capabilities. However, as mentioned in the previous section, two of the ten core capabilities (i.e. 'life' and 'practical reason') were not considered in this study because the survey did not contain information that could be used as proxies for them.

Our analysis was based on 29880 of the total 30002 individuals surveyed after dropping 122 individuals because their racial group was not made explicit in their questionnaires. This small number did not affect the representativity of the data.

\section{Choice of indicators}

Although Nussbaum's capabilities are important, not many surveys contain questions that directly refer to what is implied by each Nussbaum capability. Whereas the analysis of capabilities envisaged by Nussbaum would consider aspirations and freedoms, these are not explicitly present in the biennial GCRO QoL surveys. Scientific research suggests that where it is not possible to obtain a variable demanded by theory, a researcher can either omit the variable or use a proxy variable which reasonably captures what is implied by the missing one. The use of proxies is common in scientific research as a way of minimising specification bias resulting from omitting a variable (Frost, 1979; Huang et al., 2005). In our case, we utilised an existing dataset, which not only saved costs and time but also proved the feasibility of using the biennial GCRO QoL surveys to conduct capability analyses.

Capabilities are a consequence of 'functionings'. For example, a capability such as 'bodily health' is a combination of certain functionings/aspirations (such as having decent shelter, healthy food and clean water) and the freedom to attain them. While our data do not explicitly capture aspirations and freedoms, we did manage to observe achievements in functionings. For example, in the case of 'bodily health', the data contain information on the quality of housing and water.

Rational individuals aim to maximise their achievements. Hence, the levels of achievement observed in the data give an indication of the level of freedom available to the individual to achieve each aspiration (functioning). For example, a rational person aspires to live in a decent shelter; if one lives in a shack, this implies a lack of freedom to attain a higher status. While there can be deviations from rationality, the aspiration towards decent shelter is a reasonable assumption to make given the general expectation for 
the observance of human dignity in South Africa and the world over.

Using the available QoL IV-2015/16 data (GCRO, 2016) as a basis, we chose several proxies/ indicators to represent the respective capabilities (see Table 1). Following is a discussion on the eight capabilities we considered and the corresponding proxies we used in particular cases. Definitions for the variables listed in this section are provided in Table A (pp. 46-51)

Table 1: The eight capabilities and their corresponding indicators

\begin{tabular}{|c|c|}
\hline Capabilities & Indicators \\
\hline \multirow[t]{6}{*}{ Bodily health } & Dwelling type \\
\hline & Living space (number of rooms per capita) \\
\hline & Water quality \\
\hline & Health prevents daily work \\
\hline & Hunger \\
\hline & Subjective health rating \\
\hline \multirow[t]{4}{*}{ Bodily integrity } & Home safety \\
\hline & Safety during day \\
\hline & Safety at night \\
\hline & Safety and security services \\
\hline \multirow{2}{*}{$\begin{array}{l}\text { Senses, imagination and } \\
\text { thought }\end{array}$} & Education \\
\hline & Disability \\
\hline \multirow{6}{*}{$\begin{array}{l}\text { Control over one's environ- } \\
\text { ment }\end{array}$} & Influence on community developments \\
\hline & Voter registration \\
\hline & Perception of politics \\
\hline & Employment status \\
\hline & Business ownership \\
\hline & Social grant recipient \\
\hline \multirow[t]{4}{*}{ Affiliation } & Participation in club \\
\hline & Attitude towards foreigners staying in South Africa \\
\hline & Perceptions about the place of whites in contemporary South Africa \\
\hline & Perceptions about hitting partner \\
\hline \multirow[t]{2}{*}{ Emotions } & Nobody cares about people like me \\
\hline & Feelings of depression \\
\hline \multirow[t]{3}{*}{ Play } & Family time \\
\hline & Leisure time \\
\hline & Parks/public spaces \\
\hline \multirow[t]{2}{*}{ Other species } & Care for the environment \\
\hline & Climate change \\
\hline
\end{tabular}




\section{Bodily health}

Nussbaum considers bodily health to comprise good health, reproductive health, adequate nourishment and adequate shelter. The relationship between these factors and bodily health is well established in the literature, for example on housing conditions (Breysse et al., 2004), water quality (Hunter et al., 2010; Hutton \& Bartram, 2008) and nutrition (Hercberg et al., 2008). These aspects are critical in the South African context, where informal housing is widespread, access to clean water is not universal and food security is a problem. All these factors are recognised internationally as basic human rights and are enshrined in the South African Constitution as such (RSA, 1996; StatsSA, 2019c). To represent this capability, we used the following variables from the QoL dataset: 'Dwelling type', 'Living space (number of rooms per capita)', 'Water quality', 'Health prevents daily work', 'Hunger', and 'Subjective health rating' (GCRO, 2016).

\section{Bodily integrity}

Bodily integrity is the autonomy and self-determination a person has over his/her body. Nussbaum refers to people's mobility, safety and the freedom to make choices on reproductive and sexual matters. From this perspective, the individual is autonomous and authoritative in matters relating to his/her own body (Nussbaum, 2000b; Patosalmi, 2009; Shaman, 2008). Deeply rooted in classical liberalism, the concept of bodily integrity stretches back for centuries and refocuses attention towards individual sovereignty over one's body beyond the reach of governmental power (Mill, 1859; Patella-Rey, 2018). The US Supreme Court affirmed and made legal precedence of this concept in 1891 (Patella-Rey, 2018). In fact, John Stuart Mill considered bodily integrity and individualism as elements of human well-being because they give individuals total control over themselves, their bodies and their minds (Mill, 1859, in Patella-Rey, 2018). This conception of bodily integrity was adopted by the South African government and is enshrined as a right in Section 12(2) of the South African Constitution (RSA, 1996). However, violations of bodily integrity are ubiquitous within South African society compared to other countries in the region; and sexual offences, in particular, were reported by 88 percent of crime victims in a recent survey, which is far above the global average of 35 percent (StatsSA, 2019d; UN, 2019). The fact that many such violations go unreported suggests they could actually be far more prevalent.

Bodily integrity safeguards the physical parameters of a person and is hence important in ensuring human well-being (Neff, 1990). To represent bodily integrity, variables from the QoL dataset relating to the following factors were used: 'Home safety', 'Safety during the day', 'Safety at night', and 'Safety and security services' (GCRO, 2016).

\section{Senses, imagination and thought}

Nussbaum (2003) closely connects this capability with the basic literacy skills that come from exposure to an adequate education. As Nelson Mandela is reputed to have said: 'A good head and good heart are always a formidable combination. But when you add to that a literate tongue or pen, then you have something very special.'

South Africa suffered a long history of racial segregation, and one way of maintaining this division was to have an unequal education system in which black Africans, in particular, were disadvantaged compared to whites (Phillips, 1999). In the democratic era, the education system performs unevenly due to myriad challenges that are not easily resolvable by increasing budgets. Rather, these challenges require restitching the social fabric and instilling moral values that view education in a positive light (Mouton et al., 2013). School dropout rates in South Africa are high, with 60 percent of children dropping out before reaching Grade 12 (Weybright et al., 2017). Poor or low levels of education expose individuals to suboptimal behaviours and mental health (Fleisch et al., 2012; Fuller et al., 2002). This has adverse effects not just on individuals who are denied a decent life, but also on society in general in the form of lack of skills and the tendency towards crime that South Africa currently experiences. Two variables were used to represent this capability, namely 'Education' and 'Disability' (GCRO, 2016). We included disability as we are of the opinion that physical limitations can potentially impede a person from fully using their imagination and thought. According to Nussbaum (2000b), imagination and thought are connected with experiencing and 
producing works and events - religious, literary and musical - of one's own choice.

\section{Control over one's environment}

Citizens, in general, have a right to participate in political and developmental matters that affect them, which happens through voting, community development planning and the courts (Smith \& Rubin, 2015). In democratic societies, people's ability to make political choices is greater than in autocratic regimes. As a democratic institution, the South African government has provided several platforms through which people can engage with government, make political choices, participate in governance matters, and exercise both freedoms of speech and association. For example, citizens have a right to vote and to participate in the integrated development planning process at the local level, where they can contribute to projects and programmes in their residential areas.

Materially, the South African Constitution guarantees property rights ${ }^{5}$ and equal access to employment and business opportunities through various transformative policies such as the Employment Equity Act (1998) and broad-based black economic empowerment (B-BBEE). The implementation of these policies helps in the development of previously disadvantaged groups and individuals (Olckers \& Van Zyl, 2016). We identified a set of variables to represent this capability from our QoL data, namely 'Influence on community developments', 'Voter registration', 'Perception of politics', 'Employment status', 'Business ownership' and 'Social grant recipient' (GCRO, 2016).

\section{Affiliation}

Nussbaum considers this capability as the ability to live with and toward others, to show concern for others and to be treated with respect and dignity. This entails being treated as equal to others and as worthy, irrespective of race, sex, sexual orientation, ethnicity, caste, religion and national origin (Benbow et al., 2014; Nussbaum, 2003).

These factors generally refer to the concept of social inclusion, which Sen (2000) considered an important aspect of individual well-being. Social inclusivity dates back to Adam Smith (1776), who emphasised the importance of being able to interact freely with others. Social exclusion may induce other deprivations, thereby limiting living opportunities (Zheng \& Walsham, 2008). After many years of social exclusion, South Africa adopted a socially inclusive Constitution that recognises the various forms of affiliation as envisaged by Nussbaum. For instance, in its recognition of ethnic diversity, South Africa is regarded as a 'rainbow nation' with 11 official languages.

The following variables from the QoL data were used to represent this capability: 'Participation in club', 'Attitude towards foreigners staying in South Africa', 'Perceptions about the place of whites in contemporary South Africa', and 'Perceptions about hitting partner' (GCRO, 2016). Affiliation is not only about belonging to a group (being affiliated) but about 'Being able to live with and toward others, to recognise and show concern for other humans' (Nussbaum, 2003, p. 41).

\section{Emotions}

Emotions include mental, 'headspace' aspects that relate to how people feel about themselves and others. Emotions are subjective, psychological and expressive, and can be short and long term. According to Fredrickson's (1998) broaden-and-build theory of positive emotions, people's daily experiences of positive emotions compound over time and have an impact on a variety of life outcomes such as better physical health, longevity, higher incomes and satisfaction with life (Fredrickson et al., 2008). From our dataset, we identified two variables that came the closest in representing emotions, namely 'Nobody cares about me' and 'Feelings of depression' (GCRO, 2016). 


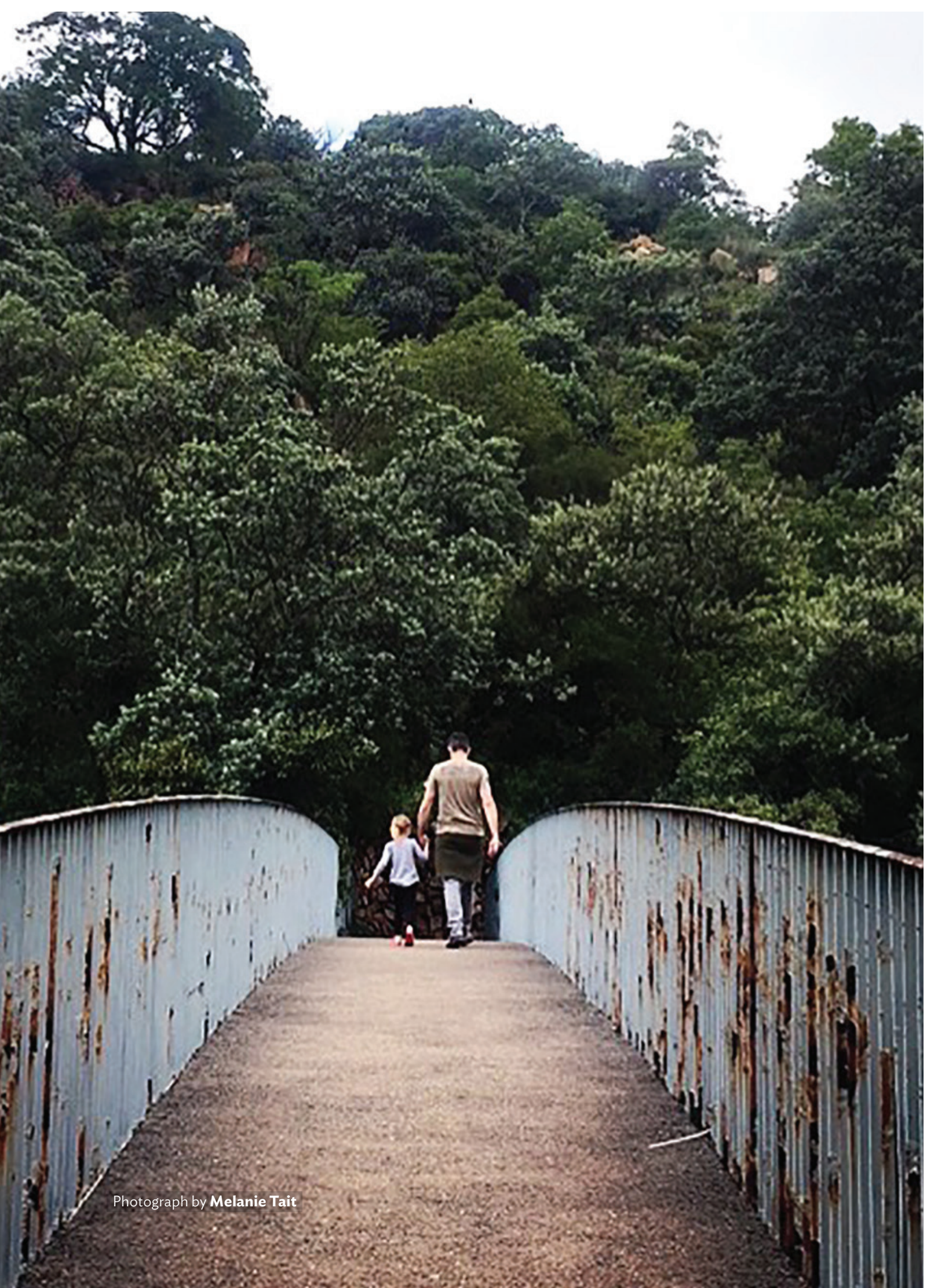




\section{Play}

Nussbaum considers play to comprise of the ability to laugh, to play and to enjoy recreational activities. In general, play is associated with children because of its contribution to their optimal development (Ginsburg, 2007). However, it is also a critical element of adult life (Barnett, 2017). It is 'roomy', encompassing a wide range of recreational activities (Eberle, 2014; Ginsburg, 2007).

Research has shown that play is associated with creativity, physical and mental well-being, and higher levels of productivity (Csikszentmihalyi, 1996; West et al., 2016). For example, Kim et al. (2014) argue that serious engagement in leisure activities leads to happiness and life satisfaction, and to successful ageing among older adults. In 1993, the National Sports Council was established to deracialise sporting structures and facilitate the equitable development of sport in South Africa. Currently, there is a National Sport and Recreational Plan that has been designed to equitably improve the lives of all South Africans, revitalise the delivery of sport and recreation, and build an active nation (RSA, 2013). At the local level, municipalities are responsible for providing recreational facilities such as parks, sporting facilities, community halls and centres in order to improve well-being. Accordingly, we used the following variables to represent this capability: 'Family time', 'Leisure time' and 'Parks/public spaces' (GCRO, 2016).

\section{Other species}

Care for one's environment is important for the wellbeing of both current and future generations (WHO, 2009). Nussbaum (2003) considers the ability to live with and have concern for animals, plants and the world of nature as one of the core capabilities. On a broader scale, human activities such as urban development, mining, farming and industrialisation have negative impacts on the environment that compromise environmental sustainability and thus reduce people's capabilities in this category.

South Africa predominantly uses fossil fuels (in particular, coal), which impact negatively on the environment. In and around Gauteng, there is a concentration of heavy industries, coal-fired power stations, coal-to-liquid industries, significant use of motor vehicles, and the domestic use of liquid fuel for cooking and lighting - all of which generate significant amounts of air pollution (Mushongera, 2015). Acid mine drainage across Gauteng also poses a health threat to people, plants and animals (Bobbins, 2015).

On the other hand, at individual and corporate levels, South Africa fosters a culture of recycling waste as a way of saving the environment (Oelofse \& Strydom, 2010). The country also takes animal welfare seriously through the Animals Protection Act (1962). However, these positive policy positions are often countered by practices that are profoundly harmful to animals.

This 'other species' capability was represented by two variables from the QoL dataset, namely 'Care for the environment' and 'Climate change' (GCRO, 2016).

\section{Play is associated with creativity, physical and mental well-being, and higher levels of productivity}




\section{Recoding of indicators}

The QoL survey asks a wide range of questions and the response options vary significantly. For instance, some questions have binary responses while others use Likert scales. ${ }^{6}$ To ensure that our proxy variables were all based on an ordinal scale of measurement, the indicators were recoded using a standard ordinal ranking procedure; the lowest rank indicates the worst outcomes while the highest indicates the best possible outcome $^{7}$ (see OECD, 2008). Where responses were thinly spread across categories in some questions, the categories were clustered (while preserving the ordinal ranking) in order to obtain a reasonable number of observations in each group.

\section{Methodology}

We constructed the capability indices based on the indicators identified in Table 1 . The general procedure for computing such indices entails aggregating indicator variables using a weighting scheme. Finding appropriate weights for each indicator is a daunting task. First, a choice needs to be made between equal or unequal weighting (OECD, 2008). An equal weighting procedure is simple and easy to apply; however, it fails to capture differences in relative importance that may exist across the indicators. This shortcoming can be resolved using unequal weighting, which reflects the relative importance of each indicator based on the underlying data. Unequal weighting also reduces the problem of double-counting in cases where indicators are highly correlated (OECD, 2008).
There are various ways of determining the weights, for example through public opinion, budget allocation processes, analytical hierarchy processes and conjoint analysis. The first three approaches rely on expert and public opinion to identify weights while conjoint analysis depends on the preferences revealed by survey respondents. Public opinion, budget allocation and analytical hierarchy processes may yield weights that reflect the level of urgency for intervention; however, they might not necessarily reflect the importance of the indicators. Weights might also be sensitive to the composition of the expert and public representatives' groups. Under conjoint analysis, on the other hand, the identification of weights depends heavily on the willingness of respondents to reveal their preferences truthfully. ${ }^{8}$ Two alternative, and widely used, statistical methods for obtaining weights are either principal component analysis, or factor analysis.

We applied multiple correspondence analysis (MCA), which is a generalisation of principal component analysis where the indicators of interest are categorical rather than continuous variables. It is also an objective statistical approach for generating both the appropriate indicator weights and the corresponding capability.

MCA entails applying regular correspondence analysis to the Burt matrix, ${ }^{9}$ which is distinguished as a set of all two-way cross-tabulations of the variables (Greenacre, 2007). We applied the analytical algorithm of joint correspondence analysis to the Burt matrix in order to account for the poor diagonal fit of MCA that is associated with inflated measures of variation. ${ }^{10}$ This generated

6 For example, binary responses: Yes/No; and Likert scale responses: Strongly agree; Agree; Neutral; Disagree; Strongly disagree.

7 For example, for the Health Status Indicator, a rank of 1 is assigned to individuals with very poor health; 2 for poor health; 3 for good health; and 4 for excellent health.

8 See Nardo et al. (2009) for extensive discussions.

9 This is derived from an indicator matrix characterised by transforming the whole dataset into dummy variables (Greenacre, 2007). Assuming the indicator matrix is denoted as $X$, the Burt matrix follows as the symmetric matrix $X^{T} X$, i.e. an own-transpose and post-multiplication of the indicator matrix.

10 'MCA codes data by creating several binary columns for each variable with the constraint that one and only one of the columns gets the value 1. This coding schema creates artificial additional dimensions because one categorical variable is coded with several columns. As a consequence, the inertia (i.e. variance) of the solution space is artificially inflated and therefore the percentage of inertia explained by the first dimension is severely underestimated' (Abdi \& Valentine, 2007, p. 653). See Greenacre (2007) for a further discussion. 
several dimensions containing sets of factor scores relating to each of the capability indicators. Factor scores associated with the dimension that captures the highest amount of total variation in the data (i.e. principal inertia) were used as weights for the capability indicators. Each capability index (CI) was computed as a weighted sum of the relevant indicators as shown in this equation:

$C I=\sum_{q=1}^{Q}\left(\sum_{k=1}^{K} R_{k}^{q} W_{k}^{q}\right), q \in[1,2, \ldots, Q] ; k \in[1,2, \ldots, K]$

- where $R_{k}^{q}$ denotes the $k$ th category response for the $q$ th indicator, and where $W_{k}^{q}$ is the corresponding weight.

Indices computed using MCA tend to be negative in the lower end due to negative weights, hence making it difficult to interpret the indices. For ease of interpretation, we normalised all indices using the $\min -\max ^{11}$ method so that the resultant indices are co-bounded between 0 and 1 , where 0 indicates the lowest well-being and 1 is the highest possible level.

Based on the MCA process, we generated capability indices for each individual in the sample, and the descriptive statistics for the overall sample, by demographic group (sex, race, age), income level and geographic location (municipalities). All estimations were conducted in Stata 15 software (StataCorp, 2015).
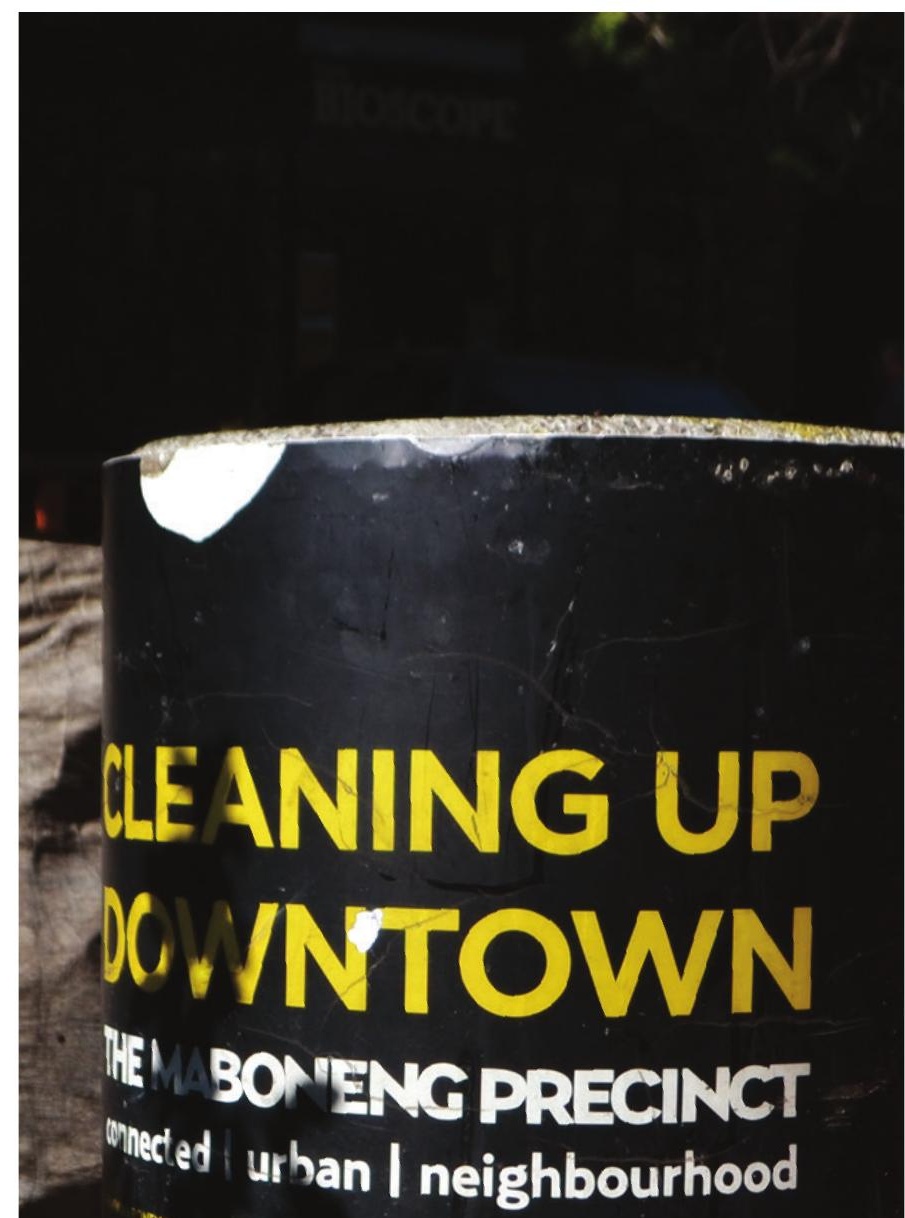


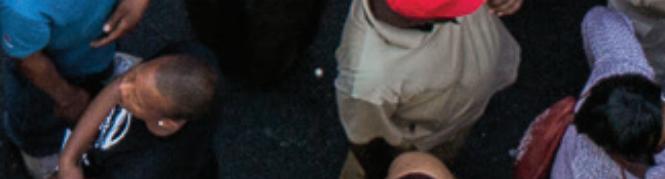

$\lambda$

(I)

es

(6)

8

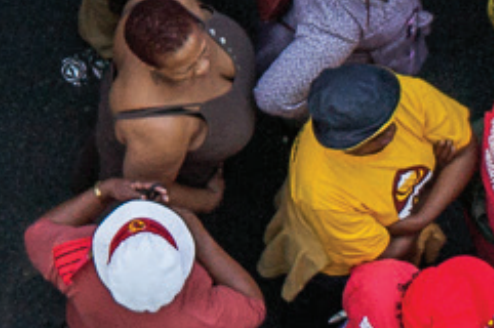

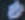
14 at?

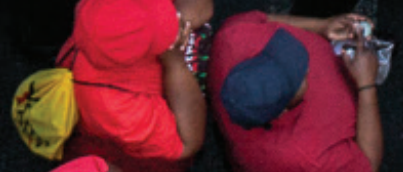
$\infty$
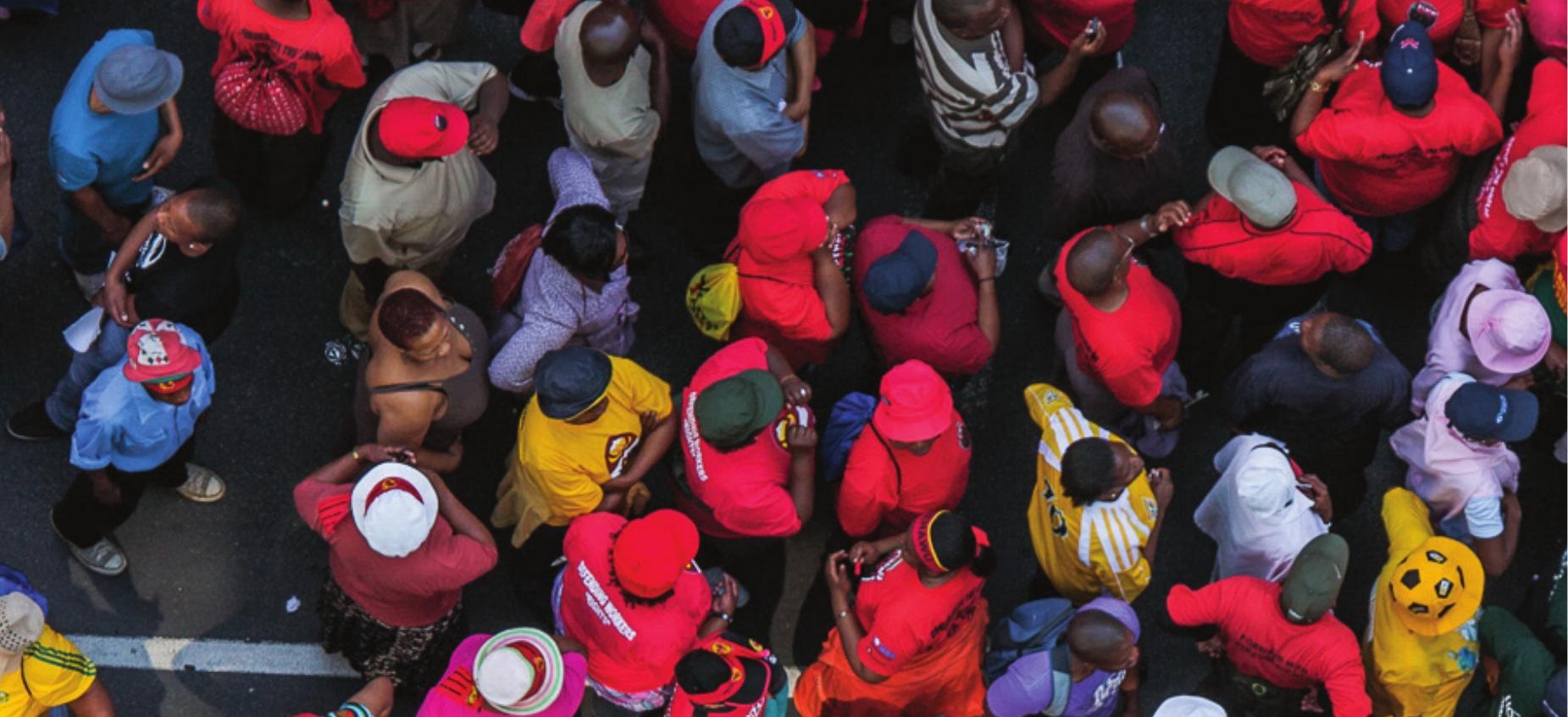
(a) 1) $x=12=1$ 4 y

का

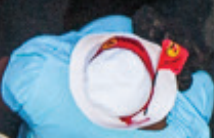

10

Cro -

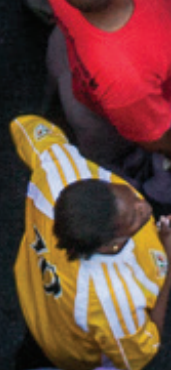
1. den ) 1010 ren $=5$ (i) $=0$ (c) ${ }^{\circ} \mathrm{C} \times \mathrm{C}$ :

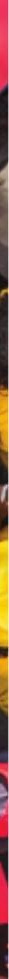




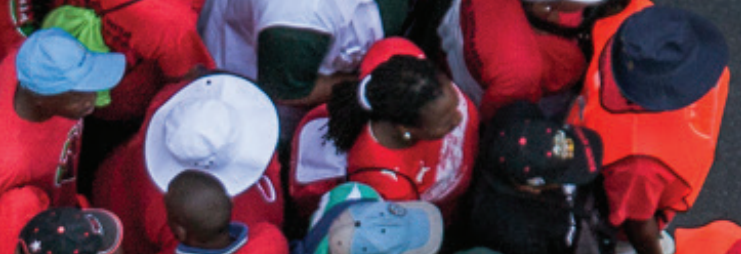

$6 \%=4$ 1. 2

if

(a)

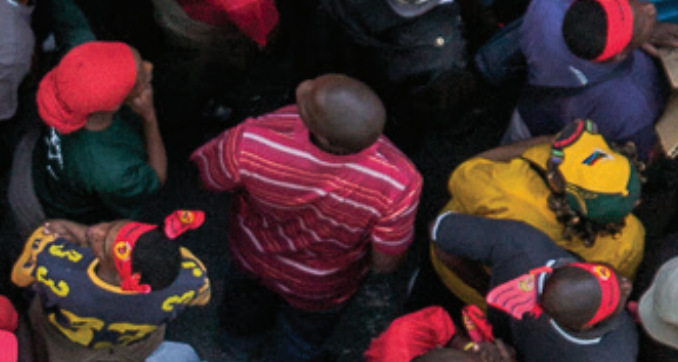

Results and analysis

(2)

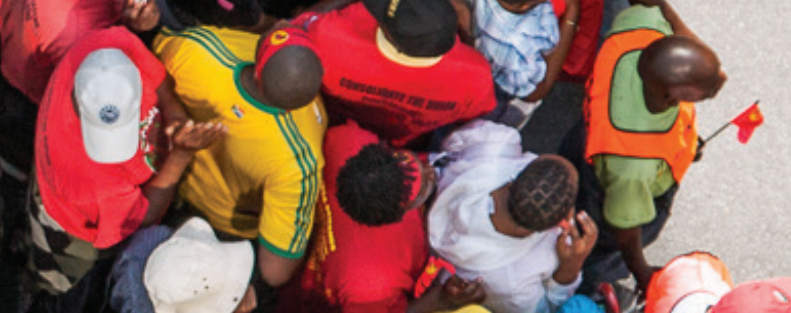

Ba.

100 C Ch

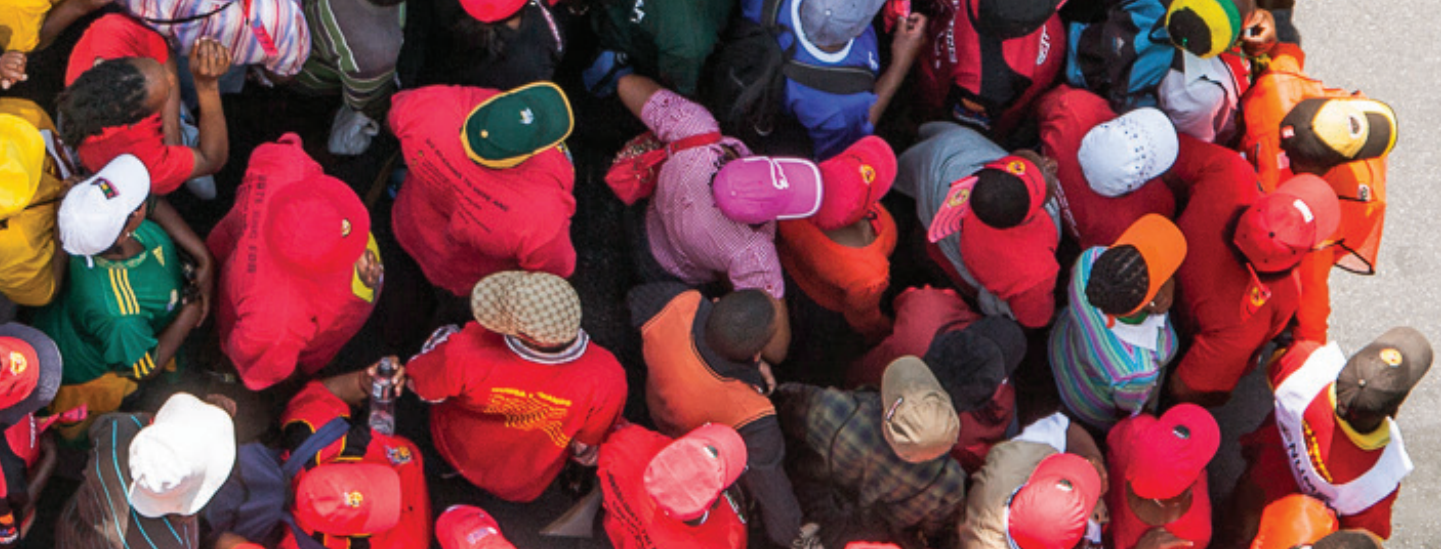




\section{Results and analysis}

For each capability, we first present the descriptive statistics of the corresponding indicators and weights attached to each indicator-response category, which were obtained from the multiple correspondence analysis. This data description gives insights into the nature of our sample as well as into the weighting structure that was used in the aggregation process to compute the capability indices. We then present our main results showing an assessment of the capability achievements by demographic group, income level and geographic location.

\section{Descriptive statistics}

For each capability, Table A in the Appendix ${ }^{12}$ shows the survey questions chosen to represent each indicator, the ordinal rank for each response (i.e. the smallest value indicates the lowest achievement while the highest value indicates the best achievement in relative terms), and the share of the sample under each response and weight. Generally, the weighting structure is intuitive, that is, negative or relatively low weights are attached to poor conditions which reduce well-being, and vice versa. Therefore, the resultant indices were consistent with the monotonicity axiom, which states that more is better. It is important to note, however, that the weights for voting in elections are somewhat counterintuitive, which potentially indicates the limited role of this variable in capturing the degree of control over one's environment.
The following is a description of the distribution of respondents across the capability indicator categories presented in Table A (the ' $\%$ share' column): ${ }^{13}$

- Bodily health: 13 percent of Gauteng residents live in informal dwellings while 40 percent live in houses with less than one room per capita. Over 80 percent of Gauteng residents have access to clean water and do not have problems with food shortages; 8 percent rated their health as poor.

- Bodily integrity: Over 70 percent of Gauteng residents feel safe during the day and at home while 28 percent feel safe walking around their neighbourhood at night; 38 percent were dissatisfied with security services provided by the government in their area. ${ }^{14}$

- Senses, imagination and thought: Gauteng residents are concentrated in three education echelons: incomplete secondary (27 percent), complete secondary (34 percent) and tertiary (26 percent). ${ }^{15} \mathrm{~A}$ small share (6 percent) reported having some form of disability.

- Control over one's environment: 80 percent of Gauteng residents are registered voters; 52 percent feel that they have influence over developments in their community. Business ownership ${ }^{16}$ stood at 9 percent.

- Affiliation: The majority (97 percent) of Gauteng residents find it unacceptable for a man to beat his partner; 77 percent are sympathetic to foreigners while 62 percent think that there is a place for

12 Presented in the Appendix due to its size.

13 Note that these statistics are weighted to reflect the population of Gauteng.

14 South Africa has high levels of violent crime. We use perceptions of safety and security services to represent bodily integrity.

15 There is a small share (2 percent) with missing information on education - the weights attached to this group are negative, which is consistent with the lower end of the education distribution.

16 This is a proxy for the material component of the dimension. Equal opportunities to work or for business ownership are considered to be materially empowering. 
whites in contemporary South Africa. Participation in social clubs or societies is modest, at 41 percent.

- Emotions: 46 percent of Gauteng residents felt that nobody cares about them while 40 percent reported feelings of depression.

- Play: 85 percent reported high levels of satisfaction with family time and 73 percent were satisfied with their leisure time. The share of residents satisfied with public spaces and parks was lower (47 percent).

- Other species: A small share (5 percent) of Gauteng residents think that it is not important to look after the environment while 19 percent were not worried about climate change.

\section{Overall capability indices}

The box-and-whisker plot ${ }^{17}$ in Figure 4 shows information on the level (median), spread (range and interquartile range), symmetry about the median, outliers and the average values for each capability (Cox, 2009; Tukey, 1977). Apart from 'affiliation', all capabilities are negatively skewed, implying there are more individuals with very low capability scores (outliers), which lowers the average more than the median.

The results suggest that there are different levels of achievement across the capabilities in Gauteng. However, we cannot directly make a

Figure 4: Capability indices - overall

SOURCE: Authors' calculations

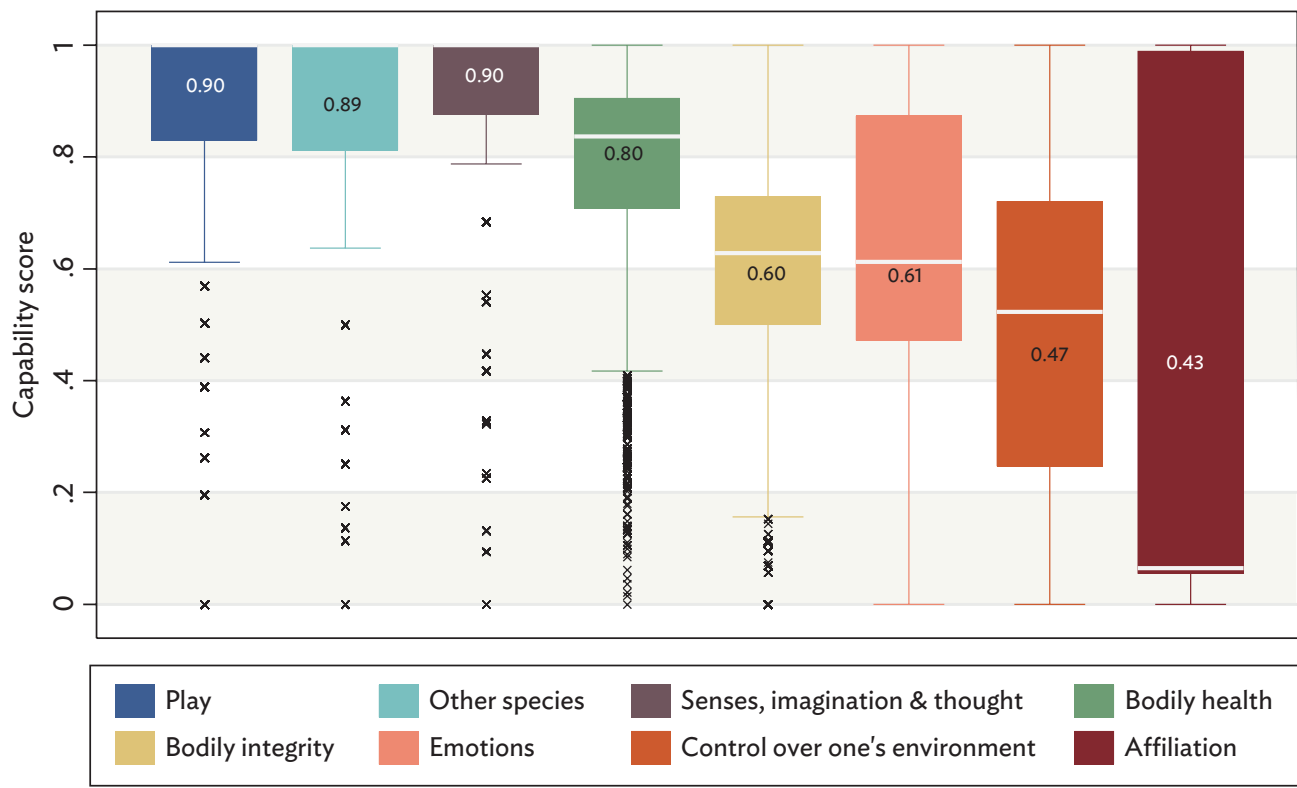

Notes: The mean values are indicated in the box-and-whisker plots; $x$ denotes the outliers 
comparison across capabilities because controlling for differences in the underlying distributions is beyond this study. Three capabilities - 'play', 'senses, imagination and thought' and 'other species' - had high scores relative to the maximum possible value of 1. 'Bodily health', 'bodily integrity' and 'emotions' are midway from the maximum possible achievement. 'Control over one's environment' and 'affiliation' have scores that are very low compared to the possible maximum value. The latter capability relates to socially accepted perceptions towards social cohesion, which includes racial tension, xenophobic attitudes, domestic violence and withdrawal from civic activities. In subsequent sections, we examine whether there is a variation in the level of capability achievement across demographic groups and space.

\section{Capability indices by demographic group}

Table 2 shows mean values for capability indices (Panel I) and median values (Panel II). On average, there were no significant gender differences in the

Table 2: Capability indices by demographic group

\begin{tabular}{|c|c|c|c|c|c|c|c|c|c|c|}
\hline & \multirow[b]{2}{*}{ Overall } & \multicolumn{2}{|c|}{ Sex } & \multicolumn{4}{|c|}{ Race } & \multicolumn{3}{|c|}{ Age group } \\
\hline & & Female & Male & $\begin{array}{l}\text { Black } \\
\text { African }\end{array}$ & Coloured & $\begin{array}{l}\text { Indian/ } \\
\text { Asian }\end{array}$ & White & Youth & $\begin{array}{l}\text { Middle- } \\
\text { aged }\end{array}$ & Elderly \\
\hline & \multicolumn{10}{|c|}{ Panel I: Mean } \\
\hline Play & 0.90 & 0.91 & 0.89 & 0.88 & 0.94 & 0.97 & 0.95 & 0.89 & 0.90 & 0.93 \\
\hline Other species & 0.89 & 0.89 & 0.88 & 0.88 & 0.87 & 0.91 & 0.90 & 0.88 & 0.89 & 0.89 \\
\hline $\begin{array}{l}\text { Senses, } \\
\text { imag. \& thought }\end{array}$ & 0.90 & 0.91 & 0.89 & 0.88 & 0.90 & 0.94 & 0.94 & 0.93 & 0.89 & 0.78 \\
\hline Bodily health & 0.80 & 0.80 & 0.79 & 0.77 & 0.79 & 0.85 & 0.86 & 0.81 & 0.80 & 0.75 \\
\hline Bodily integrity & 0.60 & 0.60 & 0.60 & 0.58 & 0.54 & 0.62 & 0.66 & 0.60 & 0.60 & 0.61 \\
\hline Emotions & 0.61 & 0.62 & 0.61 & 0.60 & 0.60 & 0.61 & 0.66 & 0.61 & 0.61 & 0.62 \\
\hline Control over env. & 0.47 & 0.44 & 0.49 & 0.45 & 0.39 & 0.54 & 0.55 & 0.50 & 0.51 & 0.21 \\
\hline \multirow[t]{2}{*}{ Affiliation } & 0.43 & 0.45 & 0.41 & 0.44 & 0.37 & 0.39 & 0.38 & 0.39 & 0.45 & 0.49 \\
\hline & \multicolumn{10}{|c|}{ Panel II: Median } \\
\hline Play & 1.00 & 1.00 & 1.00 & 1.00 & 1.00 & 1.00 & 1.00 & 1.00 & 1.00 & 1.00 \\
\hline Other species & 1.00 & 1.00 & 1.00 & 1.00 & 1.00 & 1.00 & 1.00 & 1.00 & 1.00 & 1.00 \\
\hline $\begin{array}{l}\text { Senses, imag. \& } \\
\text { thought }\end{array}$ & 1.00 & 1.00 & 1.00 & 0.88 & 1.00 & 1.00 & 1.00 & 1.00 & 1.00 & 0.88 \\
\hline Bodily health & 0.84 & 0.85 & 0.84 & 0.79 & 0.84 & 0.91 & 0.91 & 0.85 & 0.85 & 0.76 \\
\hline Bodily integrity & 0.63 & 0.63 & 0.63 & 0.61 & 0.57 & 0.67 & 0.68 & 0.62 & 0.63 & 0.64 \\
\hline Emotions & 0.61 & 0.61 & 0.61 & 0.61 & 0.61 & 0.61 & 0.62 & 0.61 & 0.61 & 0.61 \\
\hline Control over env. & 0.52 & 0.49 & 0.55 & 0.49 & 0.43 & 0.66 & 0.66 & 0.54 & 0.55 & 0.08 \\
\hline Affiliation & 0.06 & 0.06 & 0.06 & 0.06 & 0.06 & 0.06 & 0.06 & 0.06 & 0.06 & 0.06 \\
\hline
\end{tabular}


level of achievement across capabilities except for 'control over one's environment' and 'affiliation'. This also holds when considering median values, except for 'affiliation' where gender differences vanish.

Of the four race groups, black Africans and coloureds score lower on average than whites across all capabilities. When considering the median, the position of black Africans and coloureds is maintained relative to whites except for 'play', 'affiliation' and 'other species', where parity is achieved. We observe that of the four race groups, black Africans are disadvantaged on the component measures that have been compiled to represent 'senses, imagination and thought'. Indians/Asians have similar achievements to whites, except for 'bodily integrity' and 'emotions', where they have lower achievements on average. Across age groups, the elderly fare worse than others in 'bodily health' and 'control over one's environment', while youth score lower on 'affiliation'.

We find no significant differences in achievements across other capabilities by age.

\section{Capability indices by income group}

Table 3 presents capability averages and median scores by household income group. For ease of comparison, we clustered the income range in the data into four groups: income level 1 (lowest) up to 4 (highest). Overall, the results show a positive relationship between income and capability achievements. Thus, individuals in low-income households are disadvantaged compared to those in relatively higher-income households. For instance, individuals in income level 1 households have an average score of 0.71 for 'bodily health' while those in income level 2 have an average score of 0.77 . The average score increases to 0.88 for those in income level 4 households.

In terms of differences in achievement, we find for 'bodily health' a 0.17-point gap between income level 1 and income level 4 households. The corresponding figure at the median is 0.18 points. As household income increases, the differences in scores for this capability shrink to 0.03 (mean) and 0.02 (median) for income level 3 and 4 households. This pattern is exhibited across all capabilities, which highlights the aggravated positions occupied by individuals in low-income households. Noteworthy is the 'control over one's environment' capability, where the gap between individuals in income level 1 and 2 households and those in income level 4 households is 0.28 and 0.27 points. We find relatively small differences in capability scores for 'other species' and 'emotions' at the mean, but differences disappear at median values.

Table 3: Capability indices by income group

\begin{tabular}{|c|c|c|c|c|c|c|c|c|}
\hline & \multicolumn{2}{|c|}{ 1. Ro-1 600} & \multicolumn{2}{|c|}{ 2. R1 601-6400 } & \multicolumn{2}{|c|}{ 3. R6 401-25 600} & \multicolumn{2}{|c|}{ 4. $>R_{25} 600$} \\
\hline & Mean & Median & Mean & Median & Mean & Median & Mean & Median \\
\hline Bodily health & 0.71 & 0.73 & 0.77 & 0.79 & 0.85 & 0.89 & 0.88 & 0.91 \\
\hline Bodily integrity & 0.55 & 0.57 & 0.58 & 0.60 & 0.61 & 0.64 & 0.65 & 0.68 \\
\hline $\begin{array}{l}\text { Senses, imag. \& } \\
\text { thought }\end{array}$ & 0.84 & 0.88 & 0.88 & 0.88 & 0.94 & 1.00 & 0.97 & 1.00 \\
\hline Control over env. & 0.38 & 0.44 & 0.42 & 0.45 & 0.55 & 0.68 & 0.65 & 0.72 \\
\hline Affiliation & 0.39 & 0.06 & 0.45 & 0.06 & 0.44 & 0.06 & 0.48 & 0.06 \\
\hline Emotions & 0.58 & 0.61 & 0.59 & 0.61 & 0.62 & 0.61 & 0.66 & 0.62 \\
\hline Play & 0.86 & 1.00 & 0.89 & 1.00 & 0.92 & 1.00 & 0.95 & 1.00 \\
\hline Other species & 0.88 & 1.00 & 0.88 & 1.00 & 0.89 & 1.00 & 0.90 & 1.00 \\
\hline
\end{tabular}




\section{Capability indices by location}

\section{By municipality}

To gain insight into the spatial variations in capability achievements, Table 4 presents results by municipality. Panels I and II capture the average and median values of the capability indices, respectively. The 'play' capability is the most achieved in Gauteng, with average and median values of 0.90 and 1.00 , respectively. Although there are variations across municipalities, 'play' is fairly well achieved across Gauteng municipalities, where Merafong (0.96), Westonaria (0.95) and Randfontein (0.94) are the top three achievers, and Tshwane (0.89) and Lesedi (0.88) are the lowest.

The 'other species' capability is also well achieved across all municipalities. While no spatial variation is exhibited when considering median values, we observe some differences in levels of average achievement, which range between 0.84 and 0.99 points. Lesedi has the least average value (0.84), followed by Emfuleni (0.85) and Tshwane (0.88). The highest achievements are registered in Midvaal (0.99) and Westonaria (0.98). The City of Johannesburg, Ekurhuleni and Randfontein's average values coincide with a Gauteng average of 0.89 .

The status of the 'senses, imagination and thought' capability is commendable in Gauteng, with a median value of 1.00 and a mean of 0.90. Although Emfuleni, Midvaal, Mogale City and Westonaria are the lowest achievers, with a median of 0.88 and mean values of the same order, their levels of achievements are fairly high.

Overall, the achievements in 'bodily health' are reasonably high, 0.80 and 0.84 at the average and the median, respectively. Ekurhuleni (0.82) is ranked lowest in this capability while Midvaal and Merafong have the highest achievements, at 0.91. However, we noted that municipality rankings were sensitive to the choice of ranking statistic. Hence, Midvaal maintains its top rank for this capability regardless of mean or median ranking, while Tshwane, Emfuleni and Lesedi have achievements that coincide with median values for Gauteng in general. 'Bodily integrity’ achievements are modest in Gauteng, with median and average values of 0.63 and 0.60 , respectively. Based on median values, Emfuleni (0.56), Lesedi (0.58) and Randfontein (0.59) are the least performing municipalities, while Mogale City (0.67) and Tshwane (0.65) are the top performers. Ekurhuleni and Westonaria have achievements that coincide with the Gauteng median value of 0.63 .

Modest achievements are also observed for 'emotions', which has an overall mean and median of 0.61. Compared to other municipalities, Lesedi (0.37), Emfuleni (0.50) and Westonaria (0.50) score the lowest, and this ranking is the same when considering average values. Mogale City (0.87) has the highest 'emotions' capability achievement.

We find generally low achievements in 'control over one's environment' and 'affiliation' capabilities. Pertaining to the former, municipality rankings based on median values show the lowest achievers to be Emfuleni (0.45), Midvaal (0.49) and Randfontein (0.49). In contrast, Merafong (0.69) and Westonaria (0.66) have the highest scores. The position of Merafong and Westonaria as top performers is consistent across mean and median statistics. For 'affiliation', the Gauteng median and average values are 0.06 and 0.43 , respectively. No variation is evident when considering median values; however, we observe that Westonaria (0.29), Merafong (0.33) and Lesedi (0.35) have the lowest scores on average. Randfontein (0.47) has the highest average score while Mogale City (0.44), the City of Johannesburg and Tshwane have scores which approximate the Gauteng average of 0.43 .

\section{By ward}

To obtain a nuanced picture of spatial variations in the capability achievements in Gauteng, we plotted the average index scores for each capability by ward. While the municipal analysis showed both high and low achievements as typical of peripheral municipalities, the analysis by ward shows these achievements are concentrated in specific wards, and not in all of them. Wards in centrally located municipalities such as Johannesburg, Tshwane and Ekurhuleni score highly in most capabilities.

Figure 5 shows ward plots of the eight capabilities in comparative terms. The deeper red represents wards that have the highest achievement while the lighter red shows lower achievements. 


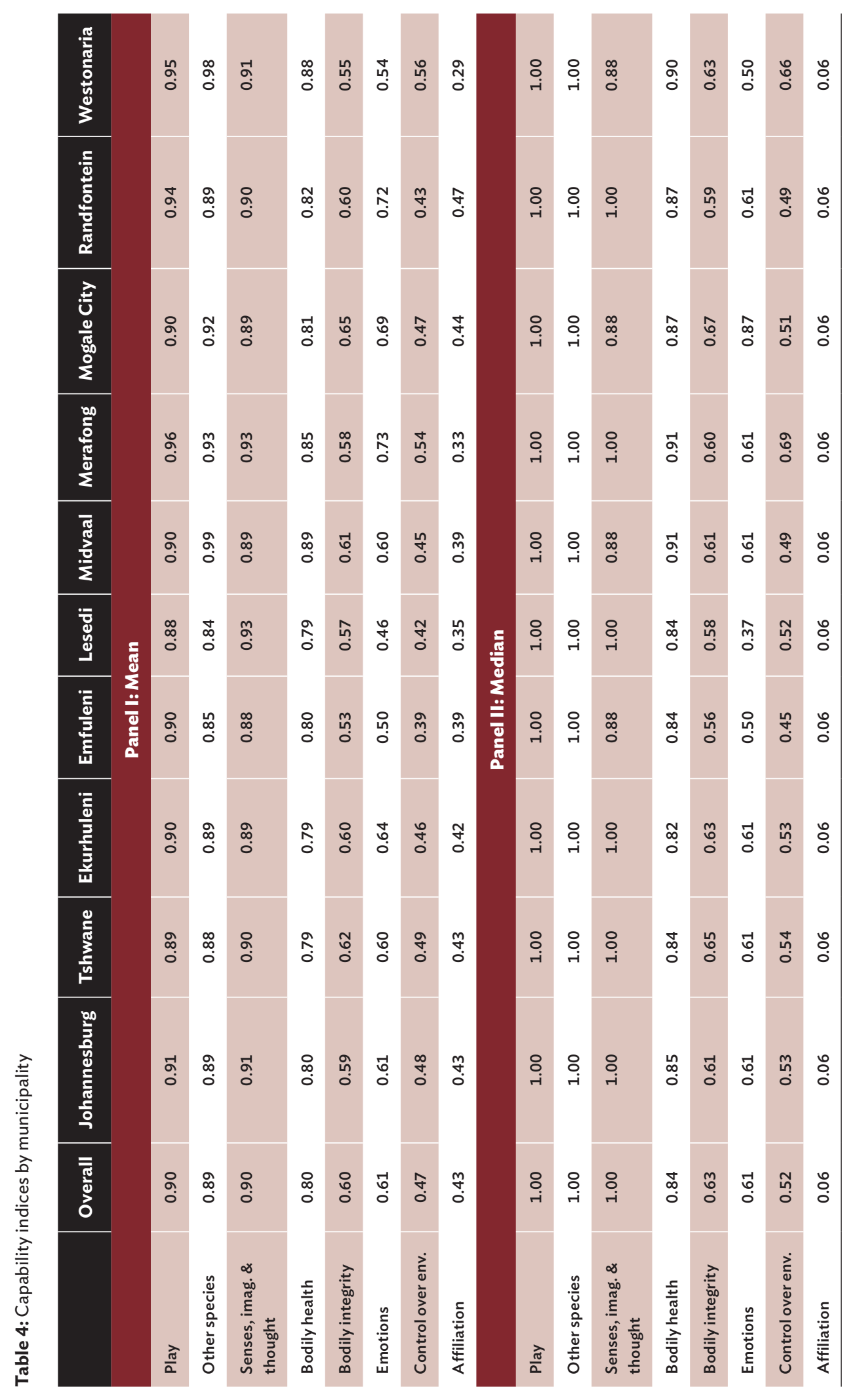


Figure 5: Capability indices by ward

DATA SOURCES: Municipal Demarcation Board (2011) Local municipalities; Municipal Demarcation Board (2011) Wards boundaries; Municipal Demarcation Board (2011) Gauteng boundary. Maps drawn by Samkelisiwe Khanyile using authors' calculations.

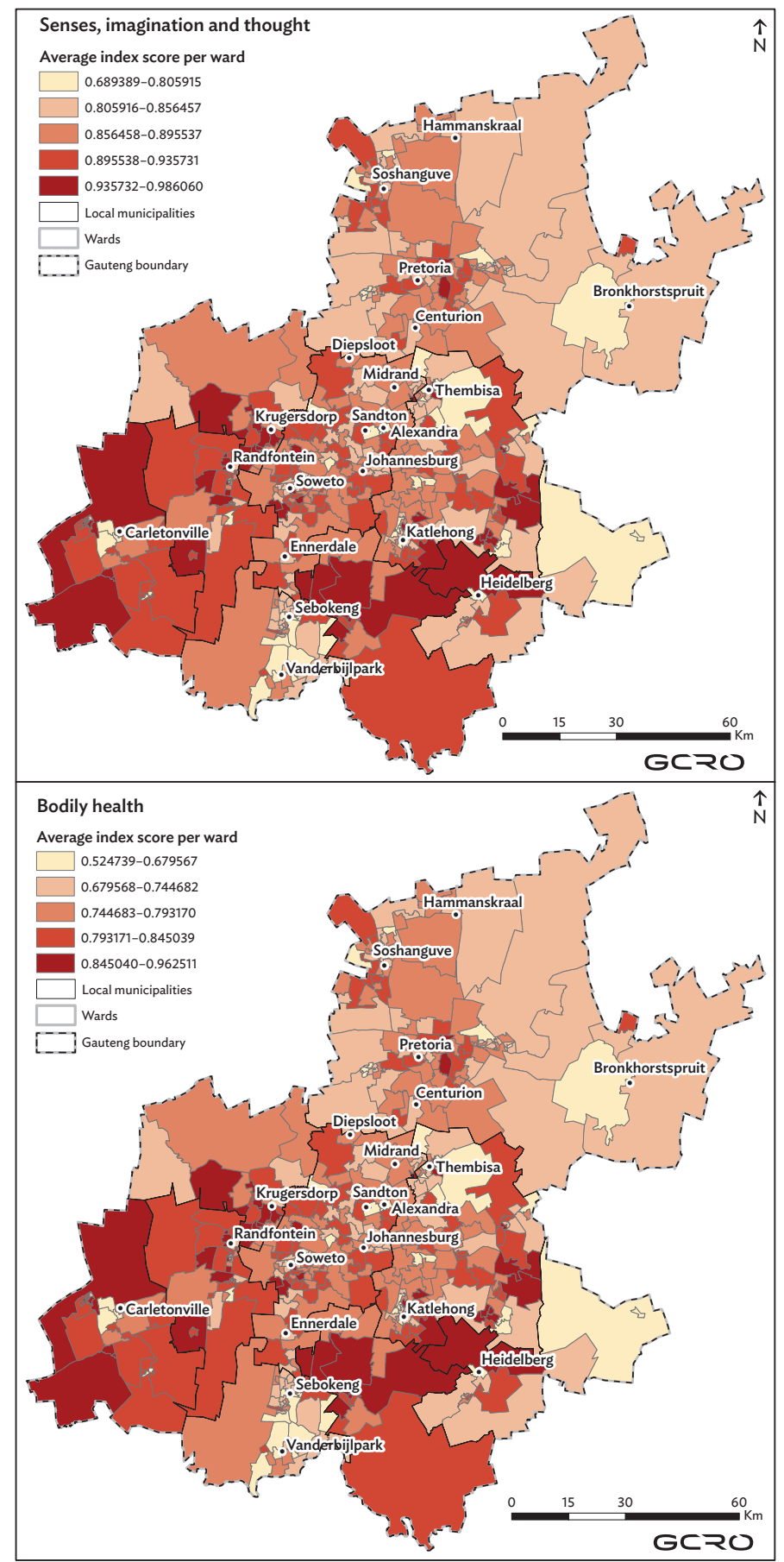


RESULTS AND ANALYSIS

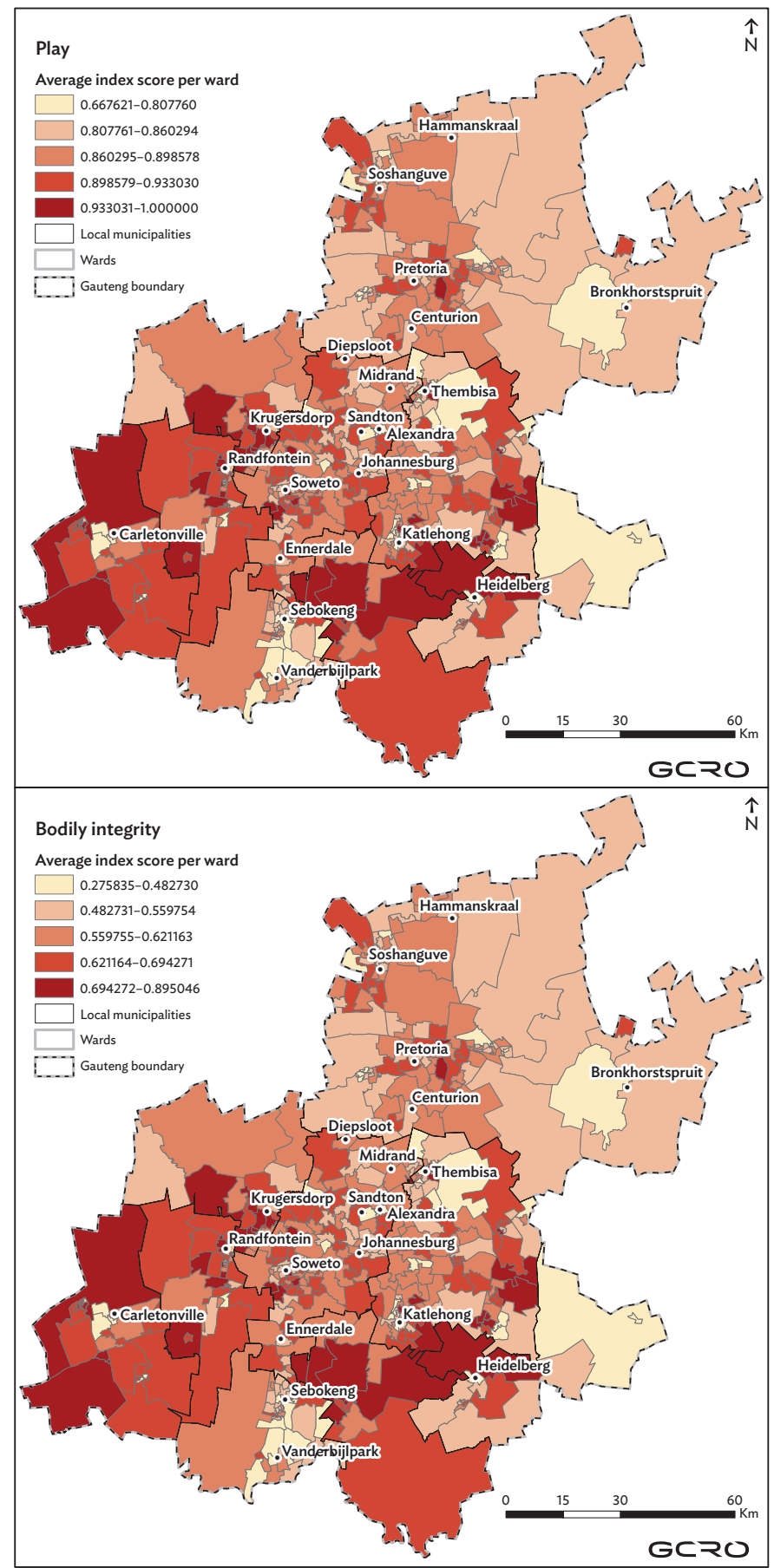


Figure 5: Continued

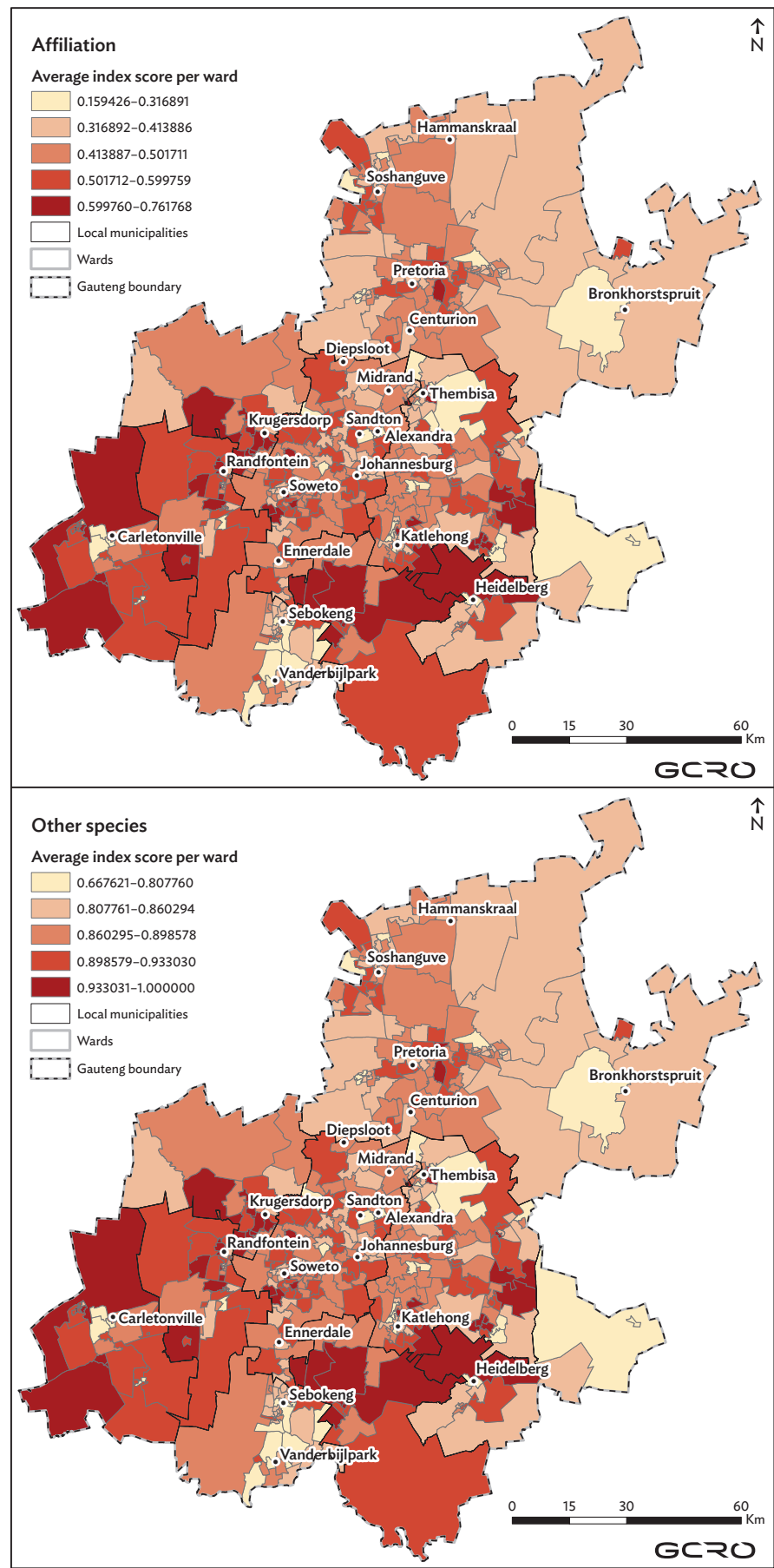


RESULTS AND ANALYSIS

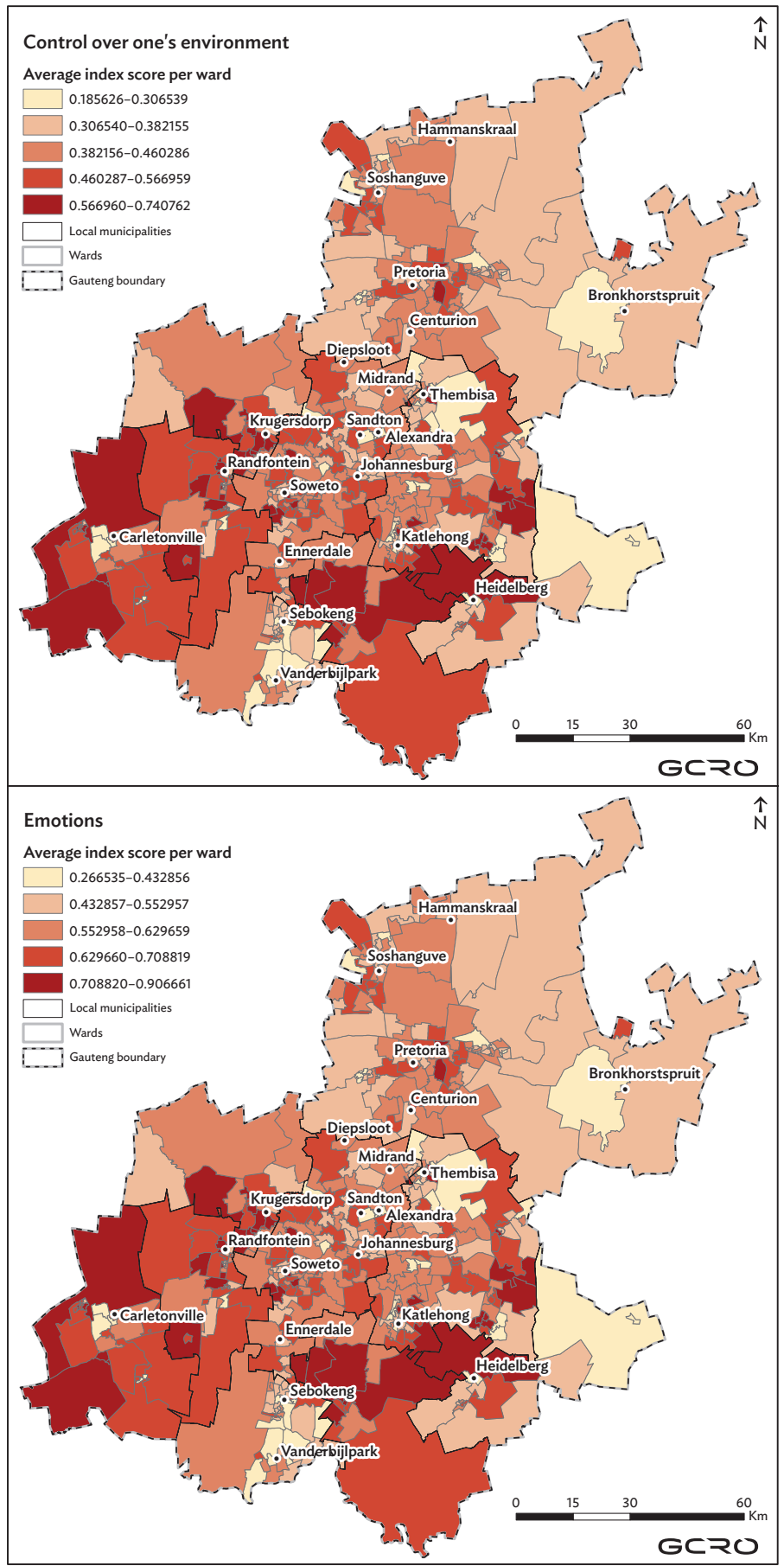


There is no consistent picture in the spatial distribution of achievements across all the eight capabilities. This result runs contrary to what is normally observed when looking at material/objective measures of well-being, where peripheral wards would show lower achievements. In fact, in this particular case, several wards in the periphery exhibit some very high achievements, particularly for 'emotions', 'affiliation' and 'other species'.

High achievements for 'senses, imagination and thought', 'play' and 'bodily health' were mostly concentrated in wards located in the central part of the province. This is understandable as most of the central wards are largely in the metropolitan municipalities of Johannesburg, Tshwane and Ekurhuleni. Here, there are better educational facilities that foster better senses and imagination, better leisure facilities and greater affinity for play by affluent households. Similarly, centrally located wards have better health facilities for both lower- and high-income housesholds, which allow them to maintian high levels of bodily health. However, there are several wards in these metropolitan areas that score very low in these capabilities. These are the usual areas where poverty has been found to be high, such as in Katlehong in the east, Alexandra, Thembisa and parts of Soweto, Sebokeng to the south and Carletonville to the far west of the province. These are high-density, low-income areas, with varying degrees of informal housing in some quarters.

For 'bodily integrity', we observed that the highest achievers were wards located on the central belt of the province, stretching from the west to the north-eastern parts. 'Bodily integrity' covers aspects of safety and most wards along this stretch fall in surburbs where security facilities are better and, in some instances, where there are gated communities. These areas include Sandton,
Centurion and Pretoria East. However, we did find outlying areas in the West Rand, Bronkhorstspruit and parts of Soshanguve where 'bodily integrity' scores very highly. Many Johannesburg wards scored very poorly on this capability, particularly in the southern half, which includes the inner city, parts of Soweto and south Johannesburg - areas known for their high levels of crime. A particular place of interest is Diepsloot, with the lowest score. Diepsloot is a semi-informal, high-density residential area to the north west of Johannesburg with a particularly high incidence of crime.

The result for 'affiliation' by ward is quite interesting in that it shows low achivement across most wards in the province. This is particularly so in the central parts of the province. As we noted earlier, it is mostly communities located on the outskirts of the province that tend to mobilise themselves into social groups, compared to those at the core who are largely well-off, who are less likely to do so. In other words, community engagement is greater in poorer areas.

A contrasting picture is obtained for 'control over one's environment', where wards that are at the centre score highly compared to those on the periphery. It appears that these centrally located communities have the ability to control their environment by exercising their right to vote, have better status and probably own businesses, and hence fare much better than those on the periphery where business and employment opportunities are limited. We noted that communities in Soweto, Sebokeng, Katlehong, Thembisa,

Soshanguve and Atteridgeville are similarly affected, and these are either high-density, low-income areas or informal settlements.

Lastly, 'other species' scored highly for wards to the west and south west of the province compared to the north and north east. Overall, this capability is well achieved. 


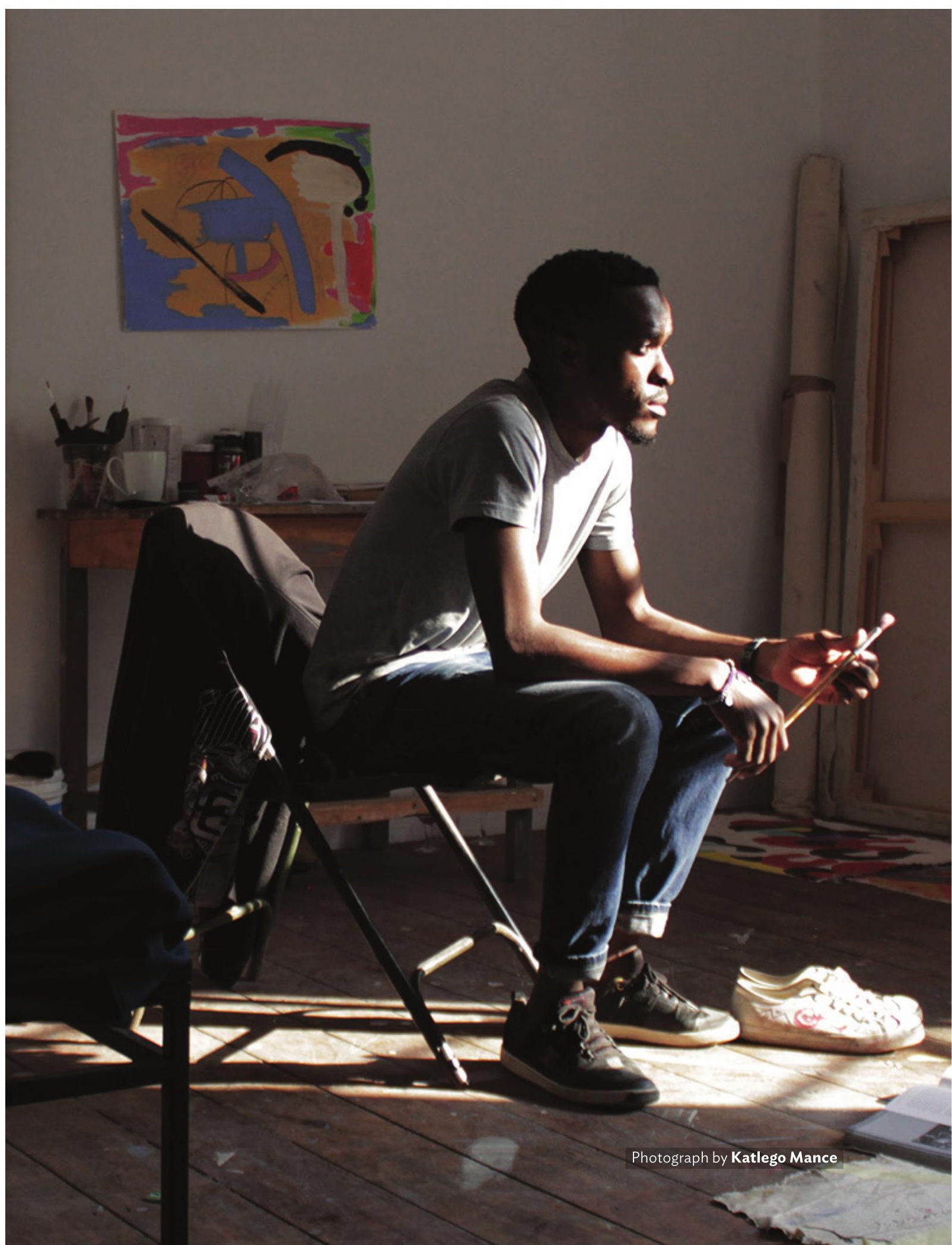


a

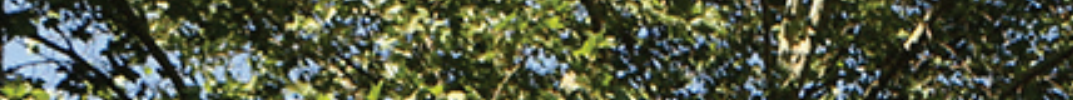

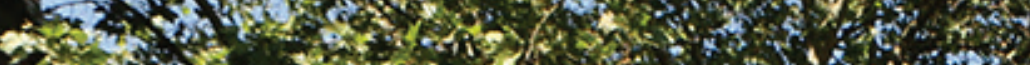

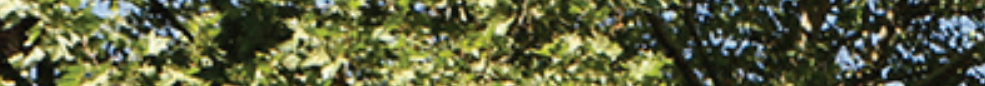

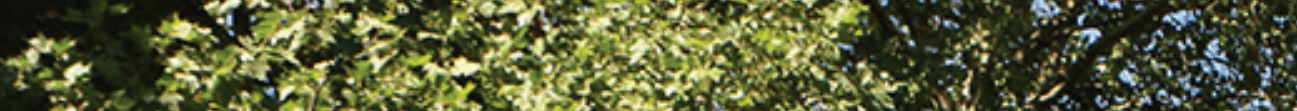

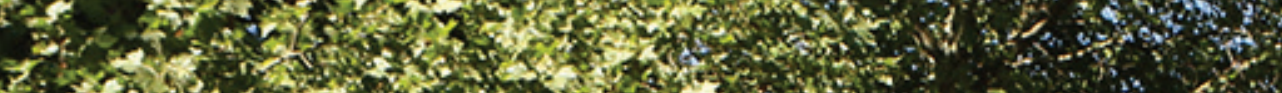

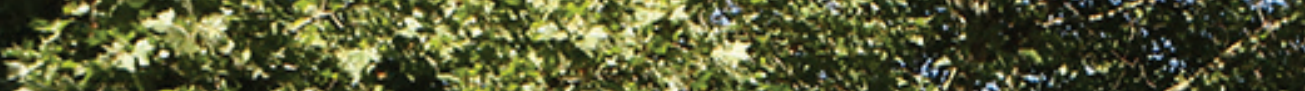
For

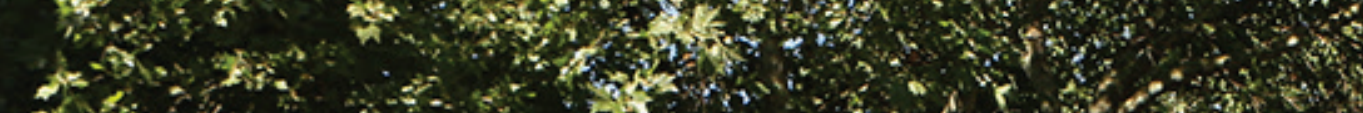
$y^{2}$ a

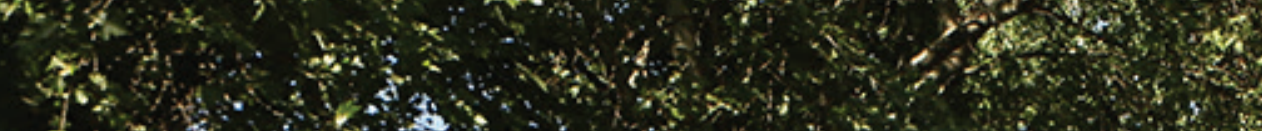

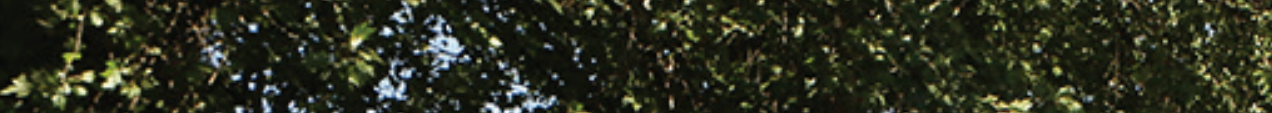

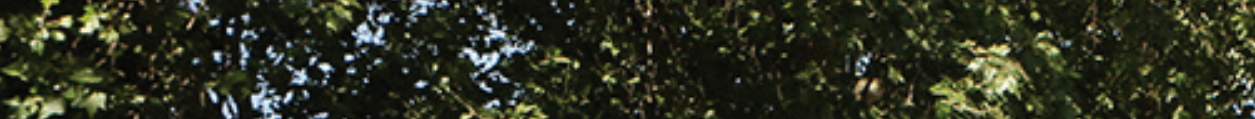

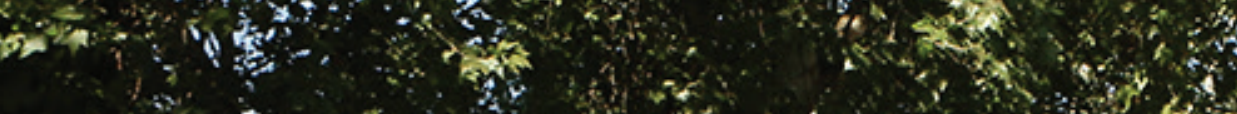
s.t.

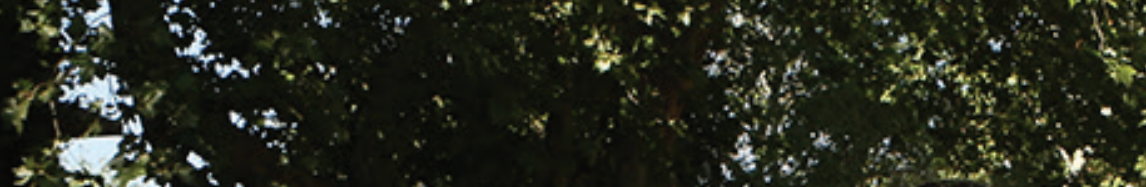

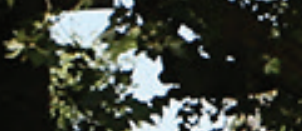

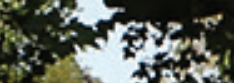
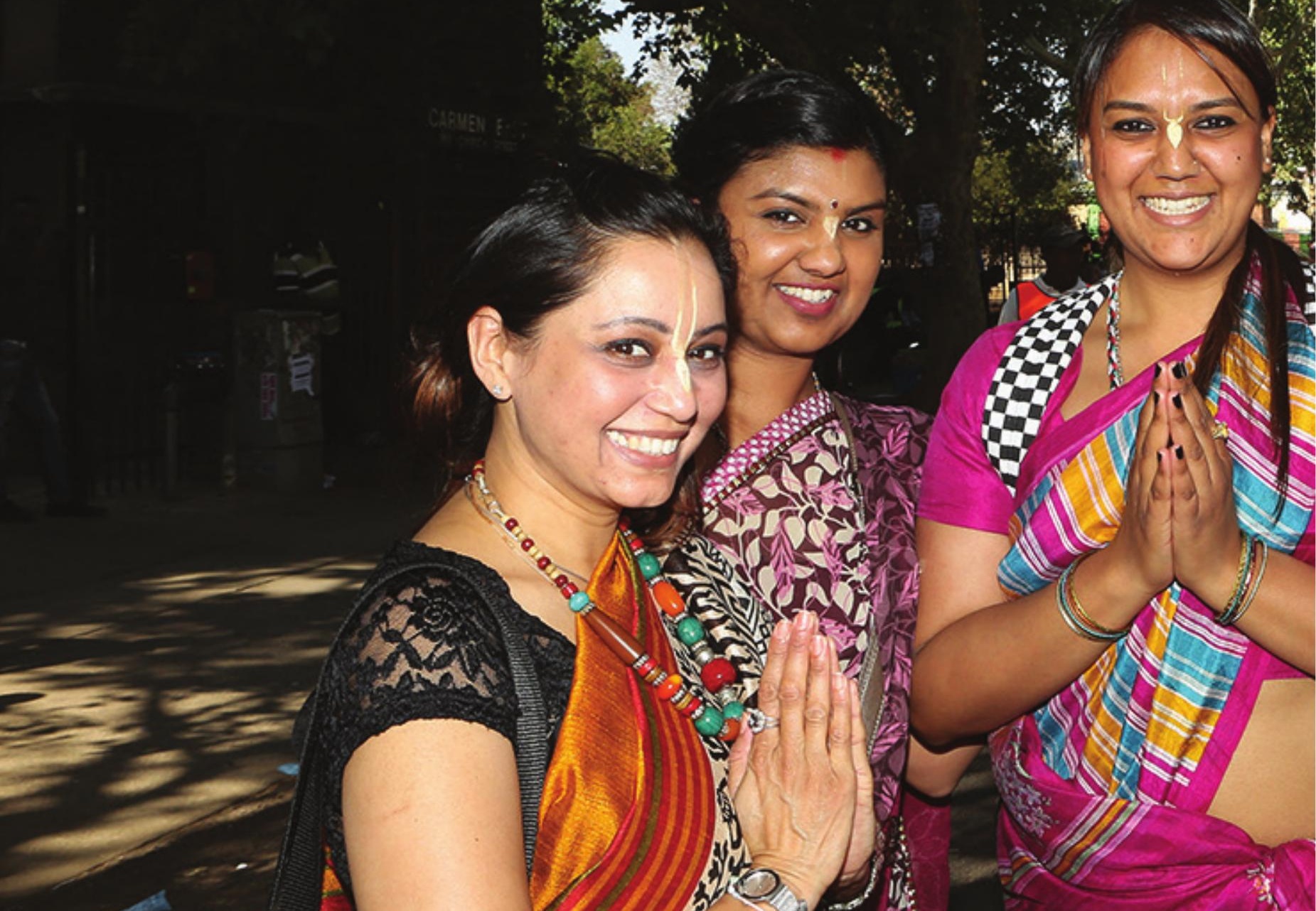

Photograph by Debbie Yazbek

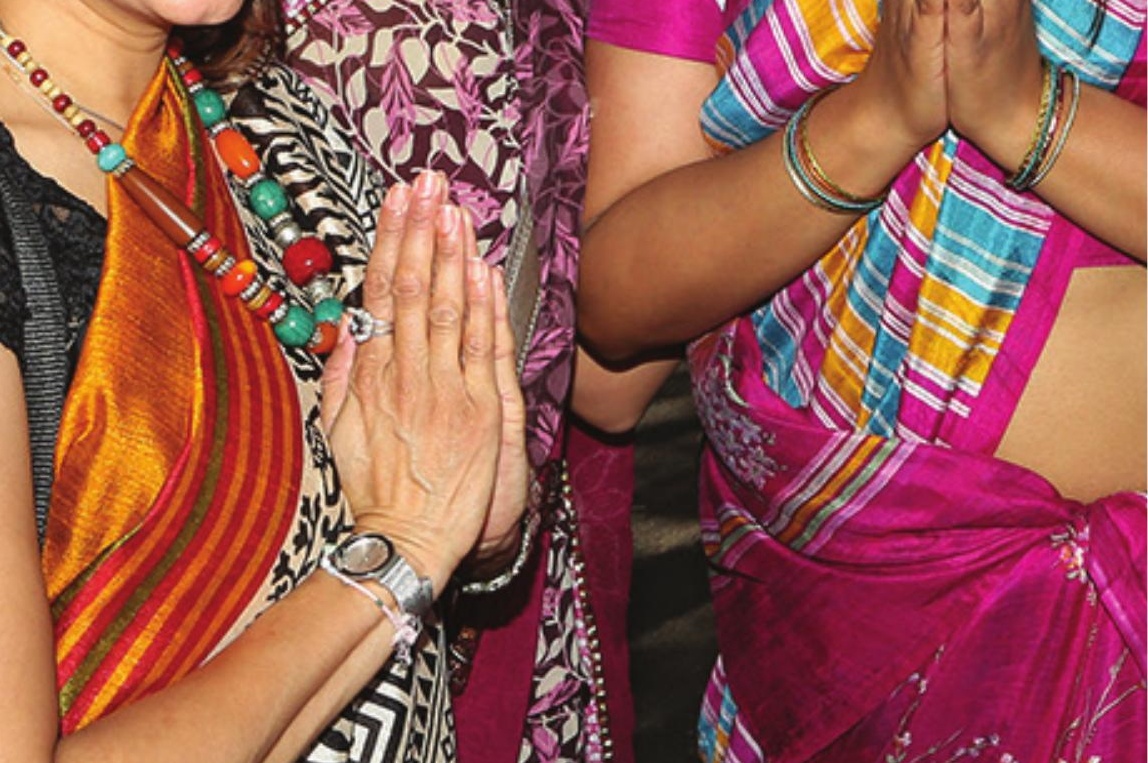




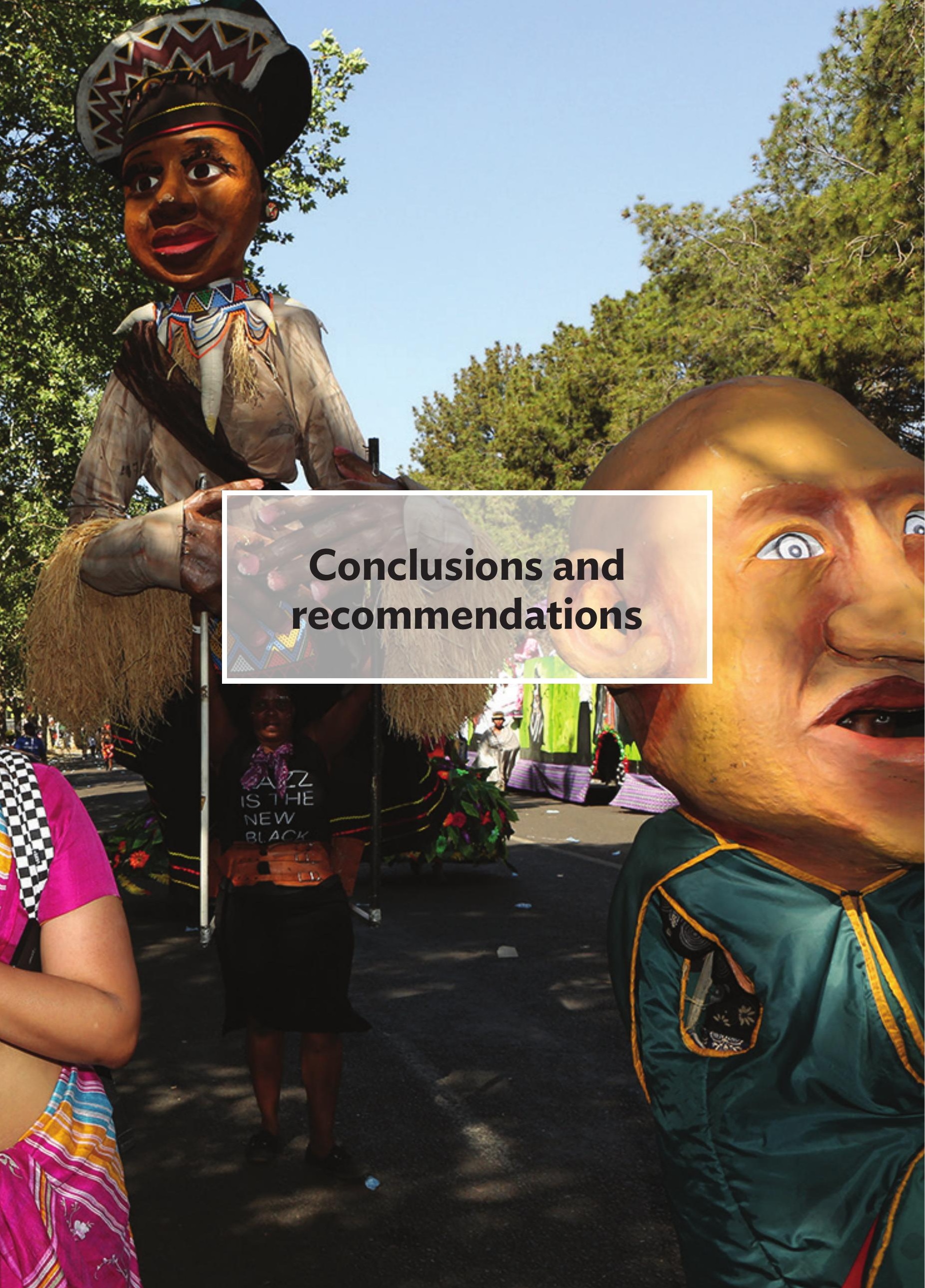




\section{Conclusions and recommendations}

Given the persistently high levels of poverty and inequality in many countries in the global South, the need to raise individual and societal well-being is paramount. In these countries, policies in place to achieve this objective are based largely on conventional methods of assessing and analysing poverty and inequality. However, conventional monetary methods, for example, fail to assess people's intrinsic values to a large extent, and hence understate well-being.

In line with the extant literature acknowledging the reality of well-being as much more complex, our analysis of well-being in Gauteng integrates objective and subjective measures to better capture this complexity. We use Amartya Sen's capability approach, which provides an overarching framework of well-being, and hence a holistic view. The central focus of this approach is the individual and the conditions that frame what each individual is willing and able to be.

According to Nussbaum, who operationalised this approach, any analysis of poverty and inequality needs to emphasise issues of justice, freedom and the need for a decent life (Nussbaum, 2011). However, there are relatively few studies that classically apply the capability approach using Nussbaum's core capabilities. This paper contributes to filling this gap by using data from the GCRO QoL Survey IV-2015/16 (GCRO, 2016) for Gauteng province, South Africa. Given that the QoL survey was not specifically designed to capture the exact capabilities Nussbaum identifies, we have adopted a proxy approach. The proxy approach is common practice in scientific research as a way of minimising specification biases that result from the omission of a variable.
From the perspective of a capability approach, individual well-being is dependent on 'functionings' that represent an individual's aspirations. A set of functionings that is coupled with the freedom to achieve them constitutes a capability. As such, variation in capabilities across individuals depends heavily on differences in both the individuals' freedoms and in any preferences they might have. This explains why two individuals belonging to the same income group may have varying capabilities; and it is for this reason that the capability approach is better placed to evaluate an individual's welfare as compared to, for example, purely income-based approaches. Accordingly, the capability approach is also more appropriate for assessing the extent to which individual rights and freedoms contained in the South African Constitution (RSA, 1996) have been realised.

We computed indices for eight of Nussbaum's ten core capabilities using a multiple correspondence analysis, and then examined their distribution and estimated differentials across sex, age and race, income group and geographic location. The outcome was more informative than a composite index because we were able to unpack the relative achievements for each individual across various indicators.

Our overall results indicate that while the capabilities of 'play', 'senses, imagination and thought' and 'other species' have high scores in the province, 'bodily integrity' and 'affiliation' have lower scores. Thus, improvements in welfare could be achieved by enhancing the status of the indicators underlying this particular capability, for example, safety, security and the ability to participate in social clubs and societies. This observation about 'bodily integrity' is consistent

\section{The central focus of the capability approach is the individual and the conditions that frame what each individual is willing and able to be}


with the high level of crime in Gauteng, which limits an individual's ability to move and live securely.

In the case of 'affiliation', the poor performance (low achievement score) largely reflects the minimal participation in social clubs and societies in Gauteng a feature possibly shaped by the diverse nature of the province's population and the rise of exclusive gated communities.

When disaggregated by demographic characteristics, namely sex, race and age, our results show very small gender differentials across capabilities. This is in contrast to the common South African finding that demonstrates considerable gender differentials in well-being. What did stand out in our analysis, however, is that women are more deprived in the 'control over one's environment' capability than men. This result is partly driven by the gender gap in economic status, where women are worse off than men, as well as by the patriarchal nature of political and community leadership in the country. In mitigation, the government should work to improve women's economic and leadership status in Gauteng.

When the data are analysed through the lens of race, huge disparities between black and white South Africans stand out. Racial segregation deliberately locked black Africans into overcrowded and underserviced townships. In Gauteng, where the space economy is predominantly urban, apartheid geography is very visible. The majority of the poor live in townships, particularly to the south-western part of the province. Although the post-apartheid government prioritised the reduction of poverty and inequality, these challenges remain (NPC, 2011). To combat this challenge, the government needs to intensify inclusive socio-economic development, thereby lifting people out of poverty.

Capability achievements also vary by age. For example, the elderly score poorly in 'bodily health' compared to the youth and middle-aged cohorts. Strategies to improve the elderly's living conditions and access to healthcare are therefore essential.

Scores by income level show that individuals from low-income households obtain lower achievements in some capabilities compared to those from relatively high-income households. This emphasises the importance of increasing household income for the poor in order to raise their capability achievements. Policies to mitigate this could include interventions aimed at improving entrepreneurial and job opportunities, and providing social grants.

The spatial analysis shows that capability achievements are heterogeneous across and within municipalities. This suggests that government interventions to improve capability scores should be area specific. We also recommend that priority be accorded to informal settlements, which exhibit widespread deprivation.

Our results for commonly analysed dimensions (i.e. objective measures) are consistent with previous South African studies. This study, however, provides additional insights into well-being by including subjective dimensions - such as play, affiliation, emotions and care for other species - which are missing in previous studies. Based on the indicators used to measure 'play' and 'other species', we find high achievement in these capabilities. There is modest achievement in 'emotions', where there is little variation across demographic groups and income level. We find spatial heterogeneity in achievements for 'emotions', with Lesedi, Westonaria and Emfuleni registering the least achievement. In contrast, Mogale City has the highest achievement, with all the other remaining municipalities somewhere in between. Concerted effort to improve this capability is required, with extra effort for the least achieving municipalities. For well-targeted policy prescriptions, it is important to conduct further enquiry into the causal factors underpinning this capability.

Generally, 'affiliation' has the lowest achievement level, with a highly dispersed distribution. It is therefore imperative that the government strengthens interventions aimed at maximising social inclusion.

Finally, we recommend that future studies on capabilities should pay attention to three key aspects. First, the underlying factors that generate deprivation in capabilities need to be explored. This may involve collecting primary data that specifically interrogate these issues. Second, dedicated studies that collect data based on Nussbaum's actual capabilities are needed to avoid reliance on proxies. Third, since Nussbaum's list was not designed to be definitive, future studies could base their capabilities more explicitly on local contexts. 


Table A: Capability indicators - descriptive statistics and weights

\begin{tabular}{|c|c|c|}
\hline Bodily health & $\%$ share & Weight \\
\hline \multicolumn{3}{|c|}{ Which type of dwelling does this household occupy (code by observation)? } \\
\hline 1. Informal dwelling/hostel/tent/other & 12.96 & -1.91 \\
\hline 2. House/brick structure/traditional house* & 87.04 & 0.28 \\
\hline \multicolumn{3}{|c|}{ How many rooms does your household occupy? ${ }^{\dagger}$} \\
\hline 1. Rooms per capita $<0.5$ & 12.82 & -1.53 \\
\hline 2. Rooms per capita $\geq 0.5$ but $<1$ & 27.24 & -0.23 \\
\hline 3. Rooms per capita $\geq 1$ & 59.94 & 0.43 \\
\hline \multicolumn{3}{|l|}{ The water you receive is: } \\
\hline 1. Never/hardly ever/sometimes clean & 4.98 & -1.84 \\
\hline 2. Usually clean & 9.92 & -0.98 \\
\hline 3. Always clean & 85.10 & 0.22 \\
\hline \multicolumn{3}{|c|}{ How often does health status prevent you from doing daily work? } \\
\hline 1. Always/some of the time & 28.67 & -1.809 \\
\hline 2. Hardly ever/never & 71.33 & 0.727 \\
\hline
\end{tabular}

In the past 12 months, how often did any adult in the household go hungry because there was not enough food?

\begin{tabular}{|l|r|c|}
\hline 1. Always/often & 2.14 & -3.061 \\
\hline 2. Sometimes/seldom & 15.26 & -2.574 \\
\hline 3. Never & 82.60 & 0.555 \\
\hline Would you describe your own health status in the past 4 weeks as: & & \\
\hline 1. Very poor & 0.95 & -4.221 \\
\hline 2. Poor & 6.89 & -3.959 \\
\hline 3. Good & 56.24 & -0.303 \\
\hline 4. Excellent & 35.93 & 1.344 \\
\hline Principal Inertia explained by dimension one & & 67.7 \\
\hline
\end{tabular}

Notes

* Structures are classified as standalone/flat/cluster, town or semi-detached house/backyard house.

${ }^{\dagger}$ Number of rooms excludes bathroom, toilet or kitchen. 


\section{Bodily integrity}

$\%$ share

Weight

How safe do you feel at home?

1. Very unsafe

6.24

$-2.928$

2. A bit safe

9.50

$-1.580$

3. Neither safe nor unsafe

9.02

$-0.722$

4. Fairly safe

0.00

0.040

5. Very safe

38.36

0.998

How safe do you feel walking in the area where you live during the day?

\begin{tabular}{|l|r|r|}
\hline 1. Very unsafe & 6.05 & -3.082 \\
\hline 2. A bit safe & 11.80 & -1.519 \\
\hline 3. Neither safe nor unsafe & 9.02 & -0.560 \\
\hline 4. Fairly safe & 42.87 & 0.196 \\
\hline 5. Very safe & 30.27 & 1.097 \\
\hline
\end{tabular}

How safe do you feel walking in the area where you live at night?

\begin{tabular}{|l|c|c|}
\hline 1. Very unsafe & 37.21 & -0.876 \\
\hline 2. A bit safe & 23.78 & -0.071 \\
\hline 3. Neither safe nor unsafe & 11.16 & 0.187 \\
\hline 4. Fairly safe & 20.73 & 0.898 \\
\hline 5. Very safe & 7.13 & 1.905 \\
\hline
\end{tabular}

How satisfied are you with safety and security services provided by the government where you live?

1. Very dissatisfied

14.73

$-1.565$

2. Dissatisfied

23.65

$-0.593$

3. Neither satisfied nor dissatisfied

21.61

0.042

4. Satisfied

32.30

0.721

5. Very satisfied

7.72

1.667

Principal Inertia explained by dimension one

48.64 


\section{Highest level of education}

\begin{tabular}{|l|c|c|}
\hline 1. No schooling & 1.74 & -3.426 \\
\hline 2. Primary & 8.60 & -2.221 \\
\hline 3. Incomplete secondary & 27.15 & -0.465 \\
\hline 4. Complete secondary & 33.74 & 0.676 \\
\hline 5. Tertiary & 26.43 & 0.676 \\
\hline 6. Missing & 2.35 & -1.275 \\
\hline Do you have a disability? & & \\
\hline 1. Yes: intellectual and multiple & 0.52 & -4.821 \\
\hline 2. Yes: hearing, sight, speech, emotional and physical & 5.25 & -3.959 \\
\hline 3. None & 94.24 & 0.247 \\
\hline Principal Inertia explained by dimension one & & 99.0 \\
\hline
\end{tabular}

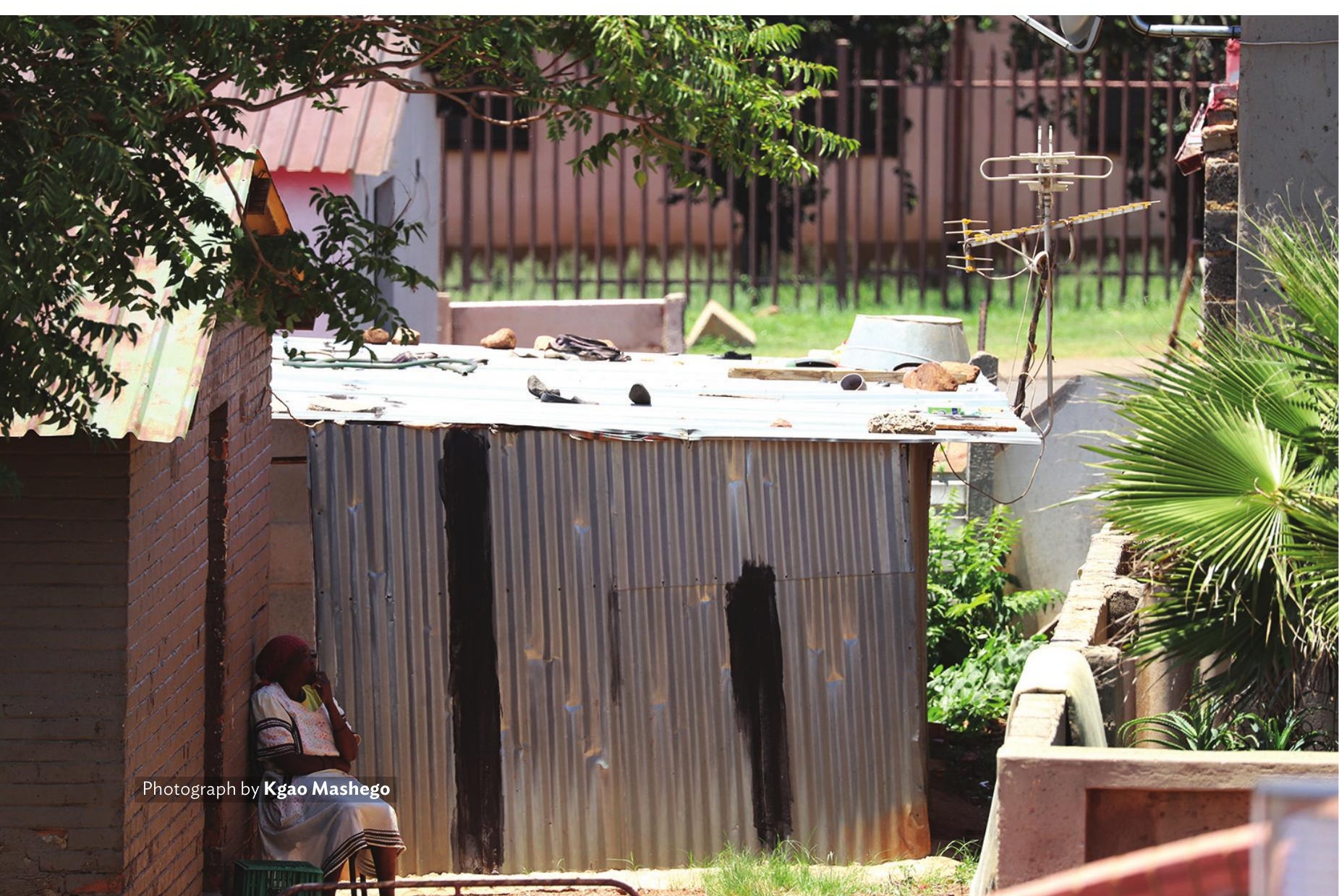




\section{Control over one's environment}

\section{$\%$ share}

30.21

17.91

51.88

20.44

79.56

0.515

1. No

2. Yes

Politics is a waste of time

A

1. Agree/strongly agree

38.24

$-0.129$

2. Neither

14.15

0.068

3. Disagree/strongly disagree

47.61

0.083

\section{Employment status}

1. Unemployed

2. Other

3. Employed

Are you currently the owner of a business, one that you were responsible for starting, even though you are not working in this business now?

\begin{tabular}{|l|c|c|}
\hline 1. No & 91.36 & -0.102 \\
\hline 2. Yes - informal & 5.41 & 0.566 \\
\hline 2. Yes - formal & 3.22 & 1.948 \\
\hline Which of the activities bring money into this household? - Grants & & -2.725 \\
\hline 1. Yes & 37.00 & 1.601 \\
\hline 2. No & 63.00 & 67.210 \\
\hline Principal Inertia explained by dimension one & & \\
\hline
\end{tabular}




\begin{tabular}{|c|c|c|}
\hline Affiliation & $\%$ share & Weight \\
\hline \multicolumn{3}{|c|}{ There is no place for white people in South Africa today } \\
\hline 1. Strongly agree/agree/neither agree nor disagree & 37.7 & -0.115 \\
\hline 2. Strongly disagree/disagree & 62.3 & 0.07 \\
\hline \multicolumn{3}{|c|}{$\begin{array}{l}\text { In the past year, have you participated in the activities of any clubs/societies } \\
\text { (e.g. religious organisation, sports club, burial societies, ratepayers, choir)? }\end{array}$} \\
\hline 1. No & 59.5 & -1.65 \\
\hline 2. Yes & 40.6 & 2.419 \\
\hline \multicolumn{3}{|l|}{ Attitude towards foreigners } \\
\hline 1. Foreigners should be sent back to their countries & 22.9 & -0.034 \\
\hline 2. Foreigners should be allowed to stay & 77.1 & 0.01 \\
\hline \multicolumn{3}{|c|}{ Is it ever acceptable for a man to hit or beat his partner? } \\
\hline 1. Yes & 2.3 & -0.052 \\
\hline 2. No & 97.7 & 0.001 \\
\hline Principal Inertia explained by dimension one & & 93.2 \\
\hline Emotions & $\%$ share & Weight \\
\hline \multicolumn{3}{|l|}{ Nobody cares about people like me } \\
\hline 1. Strongly agree & 26.98 & -0.768 \\
\hline 2. Agree & 19.39 & -1.374 \\
\hline 3. Neither agree nor disagree & 34.88 & 0.645 \\
\hline 4. Disagree/strongly disagree & 18.76 & 1.326 \\
\hline \multicolumn{3}{|c|}{$\begin{array}{l}\text { Can you tell me how you felt yesterday on a scale of } 0 \text { (did not experience the feeling) } \\
\text { to } 10 \text { (experienced the feeling): How about depressed? }\end{array}$} \\
\hline 1. Scale $9-10$ (Experienced the feeling all the time) & 6.75 & -1.223 \\
\hline 2. Scale 7-8 & 7.50 & -1.935 \\
\hline 3. Scale 5-6 & 10.56 & -1.405 \\
\hline 4. Scale 3-4 & 14.73 & -0.601 \\
\hline 5. Scale $0-2$ (Did not experience the feeling) & 60.46 & 0.768 \\
\hline Principal Inertia explained by dimension one & & 91.57 \\
\hline
\end{tabular}


How satisfied/dissatisfied are you with family life - the time you spend \& things you do with them?

1. Very dissatisfied

1.70

$-3.847$

2. Dissatisfied

7.30

$-1.756$

3. Neither satisfied nor dissatisfied

5.94

$-1.049$

4. Satisfied/very satisfied

85.06

0.301

How satisfied/dissatisfied are you with the way you spend your leisure time?

1. Very dissatisfied 3.02 $-5.756$

2. Dissatisfied 9.82 $-2.477$

3. Neither satisfied nor dissatisfied

4. Satisfied/very satisfied

14.07

How satisfied/dissatisfied are you with the parks and public spaces where you live?

\begin{tabular}{|c|c|c|}
\hline 1. Very dissatisfied & 18.79 & -0.744 \\
\hline 2. Dissatisfied & 23.21 & -0.156 \\
\hline 3. Neither satisfied nor dissatisfied & 11.42 & -0.111 \\
\hline 4. Satisfied/very satisfied & 46.58 & 0.405 \\
\hline Principal Inertia explained by dimension one & & 64.26 \\
\hline Other species & $\%$ share & Weight \\
\hline \multicolumn{3}{|l|}{ It is important to look after the environment } \\
\hline 1. Strongly disagree & 1.0 & -5.23 \\
\hline 2. Disagree & 4.2 & -4.057 \\
\hline 3. Neither agree nor strongly agree & 94.9 & 0.231 \\
\hline \multicolumn{3}{|l|}{ I am worried about climate change } \\
\hline 1. Strongly disagree & 4.0 & -2.361 \\
\hline 2. Disagree & 14.9 & -1.384 \\
\hline 3. Neither agree nor disagree & 19.4 & -0.858 \\
\hline 4. Agree/strongly agree & 61.8 & 0.754 \\
\hline Principal Inertia explained by dimension one & & 76.7 \\
\hline $\mathrm{N}$ & & 29880 \\
\hline
\end{tabular}


Dümbgen, L., \& Riedwyl, H. (2007). On fences and asymmetry in box-and-whiskers plots. American Statistician, 61, 356-359.

Eberle, S.G. (2014). The elements of play: Toward a philosophy and a definition of play. American Journal of Play, 6, 214-234.

FFC (Finance and Fiscal Commission). (2014). The impact of unfunded mandates in South Africa's intergovernmental relations. 2012/13 Report to Division of Revenue. Midrand, South Africa: FFC.

Fioramonti, L. (2014). How moving beyond GDP may help fight poverty in Africa. Global Sustainable Development Report (GSDR) 2015 Brief. New York: United Nations.

Fleisch, B., Shindler, J., \& Perry, H. (2012). Who is out of school? Evidence from the Statistics South Africa Community Survey. International Journal of Educational Development, 32(4), 529-536.

Francis, D., \& Webster, E. (2019). Poverty and inequality in South Africa: Critical reflections. Development Southern Africa, 36(6), 788-802.

Fredrickson, B.L. (1998). What good are positive emotions? Review of General Psychology, 2, 300-319.

Fredrickson, B.L., Cohn, M.A., Coffey, K.A., Pek, J., \& Finkel, S.M. (2008). Open hearts build lives: Positive emotions, induced through lovingkindness meditation, build consequential personal resources. Journal of Personality and Social Psychology, 95, 1045-1062.

Friedman, I., \& Bhengu, L. (2008). Fifteen year review of income poverty alleviation programmes in the social and related sectors. Durban: Health Systems Trust.

Frost, P.A. (1979). Proxy variables and specification bias. Review of Economics and Statistics, 61(2), 323-325.

Fuller, C.M., Vlahov, D., Ompad, D.C., Shah, N., Arria, A., \& Strathdee, S.A. (2002). High-risk behaviors associated with transition from illicit non-injection to injection drug use among adolescent and young adult drug users: A casecontrol study. Drug and Alcohol Dependence, 66(2), 189-198.

GCRO. (2016). Quality of Life Survey IV-2015/16 [Dataset]. Version 1. Johannesburg and Cape Town: GCRO \& DataFirst. https://doi.org/10.25828/w490-a496.

GCRO. (2018). Quality of Life Survey V 2017-2018 [Dataset]. Version 1.1. Johannesburg and Cape Town: GCRO \& DataFirst. https://doi.org/10.25828/8yfry-9261.

Ginsburg, K.R. (2007). The importance of play in promoting healthy child development and maintaining strong parent-child bonds. Pediatrics, 119(1), 182-192.

Greenacre, M. (2007). Correspondence analysis in practice (2nd ed.). New York: Chapman \& Hall.

Greyling, T., \& Tregenna, F. (2017). Construction and analysis of a composite quality of life index for a region of South Africa. Social Indicators Research, 131, 887-930.

Harrison, P., \& Mabin, A. (2006). Security and space: Managing contradictions of access restriction in Johannesburg. Environment and Planning, B33, 3-20.

Hercberg, S., Chat-Yung, S., \& Chauliac, M. (2008). The French national nutrition and health programme:2001-2006-2010. International Journal of Public Health, 53, 68-7r7.

Higgs, T. (2007). Measuring and understanding the well-being of South Africans: Everyday quality of life in South Africa. Social Indicators Research, 81(2), 331-356.

Huang, R., Liang, Y.Y., \& Carriere, K.C. (2005). The role of proxy information in missing data analysis.

StatisticalMethods in Medical Research., 14, 457-471. 
Hunter, P.R., MacDonald, A.M., Richard C., \& Carter, R.C. (2010). Water supply and health. PLoS Medicine, $7(11)$, e1000361. https://doi.org/10.1371/journal.pmed.1000361.

Hutton, G., \& Bartram, J. (2008). Global costs of attaining the Millennium Development Goal for water supply and sanitation. Bulletin of the World Health Organization, 86(1), 13-19.

ILO (International Labour Organization). (2013). World of work 2013: Repairing the global economic and socialfabric. Geneva: ILO.

Katumba, S., Cheruiyot, K., \& Mushongera, D. (2019). Spatial change in the concentration of multidimensional poverty in Gauteng, South Africa: Evidence from Quality of Life survey data. Social Indicators Research, 145, 95-115.

Kim, J., Yamada, N., Heo, J., \& Han, A. (2014). Health benefits of serious involvement in leisure activities among older Korean adults. International Journal of Qualitative Studies on Health and Wellbeing, 9(1). https://doi.org/10.3402/qhw.v9.24616.

Kimhur, B. (2020). How to apply the capability approach to housing policy? Concepts, Theories and Challenges, Housing, Theory and Society, $37(3), 257-27 \%$.

Klasen, S. (1997). Poverty, inequality and deprivation in South Africa: An analysis of the 1993 SALDRU survey. Social Indicators Research, 41, 51-94.

Klasen, S. (2000).Measuring poverty and deprivation in South Africa. Review of Income and Wealth, 46(1), 33-58.

Koo, J., \& Lee, H. (2015). Regional capability and regional disparity: A conceptual framework and applications within Korea. International Review of Public Administration, 20(2), 121-135.

Kwenda, P., \& Benhura, M. (2018). Labour market inequalities in the Gauteng City-Region. In D. Mushongera et al. (Eds.), Poverty and inequality in the Gauteng City-Region (pp. 48-70). Gauteng City-Region Observatory Research Report No. 9. Johannesburg: GCRO.

Landman, L., \& Badenhorst, W. (2015). Gated communities and spatial transformation in Greater Johannesburg. In P. Harrison, G. Götz, A. Todes, \& C. Wray (Eds.), Changing space, changing city: Johannesburg after apartheid (pp. 215-229). Johannesburg: Wits University Press.

Mill, J.S. (1859). On liberty. London: John W. Parker and Son.

Mouton, N., Louw, G.P., \& Strydom, G. (2013). Critical challenges of the South African school system. International Business and Economics Research Journal, 12(1), 31-44.

Municipal IQ. (2019). Municipal data and intelligence. Johannesburg: Municipal IQ.

Mushongera, D. (2015). The GCRO Barometer 2014. Gauteng City-Region Observatory Occasional Paper No. 9. Johannesburg: GCRO.

Mushongera, D. (2017). Beyond GDP in assessing development in South Africa: The Gauteng CityRegion Socio-Economic Barometer. Development Southern Africa, 34(3), 330-346.

Mushongera, D., Tseng, D., Zikhali, P., Ngwenya, P., Kwenda, P., \& Benhura, M. (2018). Poverty and inequality in the Gauteng City-Region. Gauteng City-Region Observatory Research Report No. 9. Johannesburg: GCRO.

Mushongera, D., Zikhali, P., \& Ngwenya, P. (2017). A multidimensional poverty index for Gauteng province, South Africa: Evidence from Quality of Life survey data. Social Indicators Research, 130, 277-303.

Nardo, M., Saisana, M., Saltelli, A., Tarantola, S., Hoffman, H., \& Giovannini, E. (2009). Handbook on constructing composite indicators: Methodology and user guide. Paris: OECD. 
Neff, C.L. (1990). Woman, womb, and bodily integrity. Yale Journal of Law \& Feminism, 3(2), 327-353.

NPC (National Planning Commission). (2011). National development plan: Vision for 2030. Pretoria: NPC.

Ntenga, L. (2011). The impact of unfunded mandates in South African intergovernmental relations. Midrand, South Africa: Financial and Fiscal Commission.

Nussbaum, M. (2000a). Human capabilities, female human beings. In M. Nussbaum \& J. Glover (Eds.), Women, culture and development: A study of human capabilities (pp. 61-104). Oxford: Oxford University Press.

Nussbaum, M. (2000b). Women and human development: The capabilities approach. Cambridge: Cambridge University Press.

Nussbaum, M. (2003). Capabilities as fundamental entitlements: Sen and social justice. Feminist Economics, 9, 33-59.

Nussbaum, M. (2011). Creating capabilities: The human development approach. Cambridge, MA: Harvard University Press.

OECD (Organisation for Economic Co-operation and Development). (2008). Handbook on constructing composite indicators: Methodology and user guide. Paris: OECD.

Oelofse, S.H., \& Strydom, W.F. (2010). The trigger to recycling in a developing country: In the absence of command-and-control instruments. In Proceedings Waste 2010: Waste and Resource Management Putting Strategy into Practice (pp. 355-364). 28-29 September 2010, Stratford-upon-Avon, UK.

Olckers, C., \& Van Zyl, L. (2016). The relationship between employment equity perceptions and psychological ownership in a South African mining house: The role of ethnicity. Social Indicators Research, 127, 887-901.
Patella-Rey, P.J. (2018). Beyond privacy: Bodily integrity as an alternative framework for understanding non-consensual pornography. Information, Communication \& Society, 21(5), 786-791.

Patosalmi, M. (2009). Bodily integrity and conceptions of subjectivity. Hypatia, 24(2), 125-141.

Phillips, A. (1999). Bantu Education. The Review: A Journal of Undergraduate Student Research, 2, 22-27.

Porter, M.E., Stern, S., \& Green, M. (2015). Social Progress Index. Washington, DC: Social Progress Imperative.

Rippin, N. (2016). Multidimensional poverty in Germany: A capability approach. Forum for Social Sciences, 42(2-3), 230-255.

Robeyns, I. (2003). Sen's capability approach and gender inequality: Selecting relevant capabilities. Feminist Economics, 9(2-3), 61-92. https://doi.org/10.1080/1354570022000078024.

Robeyns, I. (2005). The capability approach: A theoretical survey. Journal of Human Development, 6, 93-114.

Robeyns, I. (2016). The capability approach. In Edward N. Zalta (Ed.), The Stanford Encyclopedia of Philosophy (Winter 2016 Edition). Stanford, CA: The Metaphysics Research Lab, Stanford University.

Robeyns, I. (2017). Wellbeing, freedom and social justice: The capability approach re-examined. Online book publication.

RSA (Republic of South Africa). (1996). The Constitution. Pretoria: RSA.

RSA. (2013). The white paper on sport and recreation for the Republic of South Africa. Pretoria: RSA. 
Sen, A. (1985). Well-being, agency, and freedom: The Dewey lectures 1984. Journal of Philosophy, 82(4), 161-221.

Sen, A. (1993). Capability and well-being. In A. Sen \& M. Nussbaum (Eds.), The quality oflife (pp. 30-53). Oxford: Clarendon Press.

Sen, A. (1999). Development as freedom. New York: Knopf.

Sen, A. (2000). A decade of human development. Journal of Human Development, 1, 17-23.

Shaman, J.M. (2008). Equality and liberty in the golden age of state constitutional law. Oxford: Oxford University Press.

Smith, A. (1776). The wealth of nations. London: W. Strahan \& T. Cadell.

Smith, L., \& Rubin, M. (2015). Beyond invented and invited spaces of participation: The Phiri and Olivia Road court cases and their outcome. In C. Benit-Gbaffou (Ed.), Popular politics in South African cities: Unpacking community participation (pp. 248-281). Cape Town: HSRC Press.

StataCorp. (2015). Stata: Release 14. Statistical Software. College Station, TX: StataCorp LP.

StatsSA (Statistics South Africa). (2018). Provincial profile: Gauteng community survey 2016. Report 03-01-09. Pretoria: StatsSA.

StatsSA. (2019a). Mid-year population estimates. Statistical Release P0302. Pretoria: StatsSA.

StatsSA. (2019b). Quarterly labour force survey. Quarter 3 2019. Statistical Release P0211. Pretoria: StatsSA.

StatsSA. (2019c). Towards measuring the extent of food security in South Africa: An examination of hunger and food inadequacy. Report 03-00-14. Pretoria: StatsSA.
StatsSA. (2019d). Victims of crime report 2018/19. Media Release 03 October. Pretoria: StatsSA.

StatsSA. (2020). Mid-year population estimates. Statistical Release P0302. Pretoria: StatsSA.

Stiglitz, J.E., Sen, A., \& Fitoussi, J.P. (2009). Report by the Commission on the Measurement of Economic Performance and Social Progress. Paris: CMEPSP.

Tseng, D. (2018). Poverty and inequality in the Gauteng City-Region: An income and expenditure analysis. In D. Mushongera et al. (Eds.), Poverty and inequality in the Gauteng City-Region (pp. 14-47). Gauteng CityRegion Observatory Research Report No. 9. Johannesburg: GCRO.

Tukey, J.W. (1977). Exploratory data analysis. Biometrical Journal, 23(4), 413-414.

UN (United Nations). (2019). Facts and figures: Ending violence against women. UN Women. https://www.unwomen.org/en/what-we-do/ ending-violence-against-women/facts-andfigures.

UN. (2020). World social report. New York: UN Department of Economic and Social Affairs.

Veenhoven, R. (2007). Subjective measures of wellbeing. In M. McGillivray (Ed.), Human well-being (pp. 214-239). London: Palgrave Macmillan.

WEF (World Economic Forum). (2020). The global social mobility report 2020: Equality, opportunity and a new economic imperative. Coligny-Geneva: World Economic Forum.

West, S.E., Hoff, E., \& Carlsson, I. (2016). Play and productivity: Enhancing the creative climate at workplace meetings with play cues. American Journal of Play, 9, 71-86.

Weybright, E.H., Caldwell, L.L., Xie, H., \& Smith, E.A. (2017). Predicting secondary school dropout 
among South African adolescents: A survival analysis approach. South African Journal of Education, 37(2), 1-11.

WHO (World Health Organization). (2009). Protecting health from climate change: Connecting science, policy and people. Geneva: WHO.

Wolff, J., \& De-Shalit, A. (2007). Disadvantage. Oxford: Oxford University Press.

World Bank. (2018). Overcoming poverty and inequality in South Africa: An assessment of drivers, constraints and opportunities.
Washington, DC: International Bank for Reconstruction and Development/World Bank.

Zheng, Y., \& Walsham, G. (2008). Inequality of what? Social exclusion in the e-society as capability deprivation. Information Technology and People, 21(3), 222-243.

Zizzamia, R., Schotte, S., \& Leibbrandt, M. (2019). Snakes and ladders and loaded dice: Poverty dynamics and inequality in South Africa, 2008201\%. Southern Africa-Towards Inclusive Economic Development Working Paper No. 33. Helsinki: SA-TIED. 


\section{About the authors}

\section{Darlington Mushongera |}

Darlington Mushongera is a Senior Researcher at the Gauteng City-Region Observatory (GCRO). With a background in economics and urban planning, Darlington's research interests span several areas including poverty and inequality, development indicators, urban governance, water services and ethnography. Darlington has worked on several research projects on multidimensional measures of poverty. He holds a Bsc in Economics (University of Zimbabwe (UZ)), MSc in Rural and Urban Planning (UZ) and an MPhil in Poverty, Land and Agrarian Studies (University of the Western Cape), and is currently pursuing a $\mathrm{PhD}$ in Town and Regional Planning at the University of the Witwatersrand.

\section{Prudence Kwenda | (iD}

Professor Kwenda holds a PhD, an MA and a BSc (Hons) in Economics. She is an Associate Professor and Head of the Economics Division in the School of Economics and Finance at the University of the Witwatersrand. Her research interests are in labour, development and family economics, with a particular focus on poverty and inequality. Her work examines several aspects of poverty and inequality in various developing countries. Prudence is also a member of the Economic History Association.

\section{Miracle Ntuli |}

Professor Ntuli holds a PhD, an MSc and a BSc (Hons) in Economics. She is an Associate Professor in the School of Economics and Finance at the University of the Witwatersrand. Her research interests are in labour and development economics with a particular focus on gender inequalities and vulnerable populations in Africa. 



\section{GAUTENG CITY-REGION OBSERVATORY}

6th Floor University Corner 11 Jorissen St (Cnr Jorissen and Jan Smuts)

Braamfontein Johannesburg Gauteng, South Africa

tel +2711 7177280 emailinfo@gcro.ac.za www.gcro.ac.za

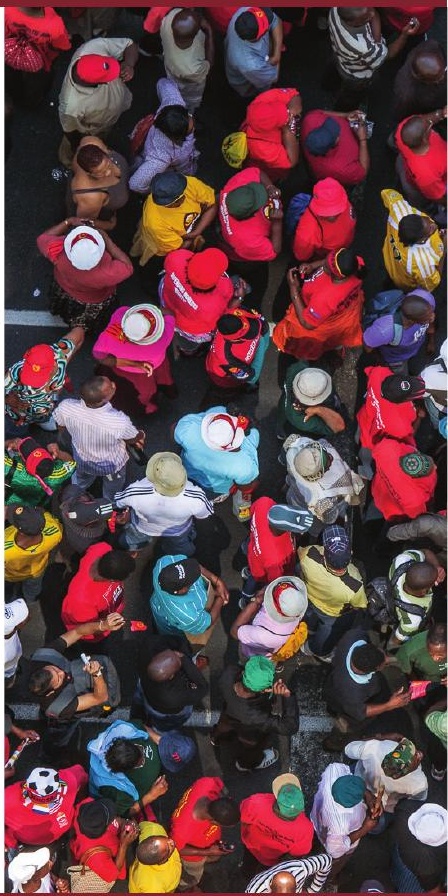

